\title{
2. SITE 595: CORING AND DOWNHOLE SEISMIC EXPERIMENTS IN THE SOUTHWEST PACIFIC NEAR THE TONGA TRENCH ${ }^{1}$
}

\author{
Shipboard Scientific Parties, with contributions by Elaine Winfrey and Patricia Doyle ${ }^{2}$
}

\section{HOLE 595}

Date occupied: 21 January 1983

Date departed: 22 January 1983

Time on hole: $17.0 \mathrm{hr}$.

Position (latitude, longitude): $23^{\circ} 49.35^{\prime} \mathrm{S}, 165^{\circ} 31.85^{\prime} \mathrm{W}$

Water depth (sea level; corrected m, echo-sounding): 5596

Water depth (rig floor; corrected m, echo-sounding): 5606

Bottom felt (m, drill pipe): 5613.5

Penetration (m): 32.5

Number of cores: 1

Total length of cored section (m): 0.5

Total core recovered $(\mathrm{m}): 0.1$

Core recovery $(\%): 20$

Oldest sediment cored:

Depth sub-bottom (m): 32.5

Nature: Pelagic clay

Age: Not determined

Measured velocity $(\mathrm{km} / \mathrm{s}):-$

Basement:

Depth sub-bottom (m): Not reached

\section{HOLE 595A}

Date occupied: 22 January 1983

Date departed: 24 January 1983

\footnotetext{
${ }^{1}$ Menard, H. W., Natland, J., Jordan, T. H., Orcutt, J. A., et al., Init. Repts. DSDP. 91: Washington (U.S. Govt. Printing Office).

2 Addresses: H. William Menard (Co-Chief Scientist, deceased), Geological Research Division (A-015), Scripps Institution of Oceanography, La Jolla, CA 92093; James H. Natland (Co-Chief Scientist), Deep Sea Drilling Project (A-031), Scripps Institution of Oceanography, La Jolla, CA 92093; Thomas H. Jordan (Co-Chief Scientist), Geological Research Division (A-015), Scripps Institution of Oceanography, La Jolla, CA 92093, (present address: Department of Earth, Atmospheric, and Planetary Sciences, Massachusetts Institute of Technology, Cambridge, MA 02139); John A. Orcutt (Co-Chief Scientist), Institute of Geophysics and Planetary Physics (A-025), Scripps Institution of Oceanography, La Jolla, CA 92093; Richard G. Adair, Institute of Geophysics and Planetary Physics (A-025), Scripps Institution of Oceanography, La Jolla, CA 92093, (present address: Rockwell Hanford Operations, Energy Systems Group, P. O. Box 800, Richland, WA 99352); Mark S. Burnett, Scripps Institution of Oceanography, La Jolla, CA 92093; Glen N. Foss, Deep Sea Drilling Project (A-031), Scripps Institution of Oceanography, La Jolla, CA 92093; Michael N. Harris, Naval Ocean Research and Development Activity, NSTL Station, MS 39529; Isaac Kim, Scripps Institution of Oceanog raphy, La Jolla, CA 92093; Arthur Lerner-Lam, Geological Research Division (A-015), Scripps Institution of Oceesilling (A-031), Scripps Institution of Oceanography, La Jolla, CA 92093; Richard Prevot, Géophysique, ORSTROM, B.P. As, Noumea Cedex, New Caledonia; Mark A. Riedesel, Scripps Institution of Oceanography, La Jolla, CA 92093; Michael H. Ritzwoller, Scripps Institution of Oceanography, La Jolla, CA 92093; Eric J. Rosencrantz, Institute for Geophysics, University of Texas at Austin, Austin, TX 78751; Peter R. Shaw, Scripps Institution of Oceanography, La Jolla, CA 92093; Peter M. Shearer, Scripps Institution of Oceanography, La Jolla, CA 92093; Deborah K. Smith, Scripps Institution of Oceanography, La Jolla, CA 92093; Kenneth M. Toy, Scripps Institution of Oceanography, La Jolla, CA 92093; S. Trowell, Naval Ocean Research and Development Activity, NSTL Station, MS 39529; C. Van Bruggen, Scripps Institution of Oceanography, La Jolla, CA 92093; Robert B. Whitmarsh, Institute of Oceanographic Sciences, Wormley, Godalming, Surrey GU8 SUB, United Kingdom; David F. Willoughby, Geological Research Division (A-015), Scripps Institution of Oceanography, La Jolla, CA 92093; with contributions by Patricia Doyle and Elaine Winfrey, Scripps Institution of Oceanography, La Jolla, CA 92093.
}

Time on hole: $47.0 \mathrm{hr}$.

Position (latitude, longitude): $23^{\circ} 49.34^{\prime} \mathrm{S}, 165^{\circ} 31.62^{\prime} \mathrm{W}$

Water depth (sea level; corrected m, echo-sounding): 5614

Water depth (rig floor; corrected m, echo-sounding): 5624

Bottom felt (m, drill pipe): 5629

Penetration (m): 88.5

Number of cores: 12

Total length of cored section (m): 88.5

Total core recovered $(\mathrm{m}): 37.47$

Core recovery (\%): 42.3

Oldest sediment cored:

Depth sub-bottom (m): 69.8

Nature: Mn-bearing pelagic clay with porcellanite and chert

Age: pre-Late Cretaceous (determined by ichthyoliths)

Measured velocity $(\mathrm{km} / \mathrm{s}): 1.4-1.9$ clays; 3.8 chert

Basement:

Depth sub-bottom (m): $69.8-88.5$

Nature: Basalt

Velocity range $(\mathrm{km} / \mathrm{s}): 4.2-5.2$

\section{HOLE 595B}

Date occupied: 24 January 1983

Date departed: 12 February 1983

Time on hole: $464.0 \mathrm{hr}$.

Position (latitude, longitude): $23^{\circ} 49.34^{\prime} \mathrm{S}, 165^{\circ} 31.61^{\prime} \mathrm{W}$

Water depth (sea level; corrected m, echo-sounding): 5615

Water depth (rig floor; corrected m, echo-sounding): 5625

Bottom felt (m, drill pipe): 5630

Penetration (m): 123.8

Number of cores: 7

Total length of cored section (m): 57.9

Total core recovered $(\mathrm{m}): 16.4$

Core recovery (\%): 28.3

Oldest sediment cored: None recovered

Basement:

Depth sub-bottom (m): $69.8-123.8$

Nature: Basalt

Velocity range $(\mathrm{km} / \mathrm{s}): 4.2-5.2$

Principal results: Holes 595 and 595A

Hole 595 consisted of a mudline core and a $32-\mathrm{m}$ core washed down to resistant cherts and porcellanites.

Hole 595A was offset $500 \mathrm{~m}$ to the east to find thick sediment above cherts to support casing below the reentry cone. We found only $36 \mathrm{~m}$ of such sediment in Hole 595A, however.

The types of sediment are described below:

0.0-36.0 m below seafloor (BSF): Brown pelagic clay with manganese nodules at the top. Recovery was $59.9 \%$. Ichthyoliths are abundant, other microfossils are absent. 
36.0-69.8 m BSF: Alternating porcellanite, chert, and dark brown, soft zeolite and radiolarian clay of Late Cretaceous and probable pre-Late Cretaceous age (based on ichthyoliths). Recovery was $19.7 \%$, but minimal in the core just above basement. Radiolarians are poorly preserved. The mean sedimentation rate was about $0.5 \mathrm{~m} / \mathrm{m} . \mathrm{y}$, but the precise age of basement is uncertain.

Below the sediments, we cored $18.7 \mathrm{~m}$ of pillow lavas and flows.

At 69.8-79.4 m BSF, we found massive olivine-poor abyssal tholeiite, and from 79.4-88.5 m BSF is tholeitic ferrobasalt. Both are fairly evolved lavas similar to those found at rapidly spreading ridges. The upper basalt is an unusual pale yellowish gray and contains sparse plagioclase, clinopyroxene, and altered olivine phenocrysts. It has abundant groundmass plagioclase but comparatively little groundmass titanomagnetite. The ferrobasalt is much darker, and also has plagioclase and clinopyroxene phenocrysts, but no olivine. The groundmass has more abundant titanomagnetite. Cooling units in the upper basalt are about $3 \mathrm{~m}$ cored diameter and in the ferrobasalt about $0.5 \mathrm{~m}$ cored diameter. Alteration is moderate, concentrated next to veins in halos $3-5 \mathrm{~cm}$ wide. The halos contain abundant iron oxyhydroxides and occur in both lava types. Alteration is less intense away from halos, affecting mainly opaques and interstitial glass. Several glass pillow rims are preserved in the ferrobasalt. Veins are filled with iron oxyhydroxides and are followed in sequence by calcite with or without green clay. Ferrobasalts are quite fractured, but calcite veining (and cementation) allowed them to be cored without difficulty and promoted good recovery.

\section{Principal Results: Hole 595B}

Hole 595B was a reentry hole drilled specifically to emplace the borehole instrument package (BIP) of the DARPA/NORDA marine Seismic System (MSS) into igneous basement. A reentry cone was lowered to the seafloor, and its casing was washed through the uppermost pelagic clays into the chert-bearing sediments. The cone was then released from the drill string, which was then rotated to $65.8 \mathrm{~m}$ BSF, where coring began. Coring reached basement at $68 \mathrm{~m}$ BSF, and igneous rocks were cored with the large diameter bit (which was required to drill a space for the lower casing-assembly shoe) to $81.5 \mathrm{~m}$ BSF. The lower casing was then lowered to the seafloor, the cone reentered, and the casing latched into position. Cement was pumped into the hole and the drill string retrieved. Following the second reentry, basement was cored with a standard $97 / 8$-in. diameter bit to $123.8 \mathrm{BSF}$.

No sediments were recovered above basalts. Only two small pieces of rock similar to the upper basalt of Hole 595A were recovered. Then $43 \mathrm{~m}$ of the same ferrobasalt as in Hole 595A were cored. Finally, $7.8 \mathrm{~m}$ of very sparsely olivine-plagioclase phyric pillow basalt, with distinctive variolitic chill margins, were cored. Recovery in basement was $29.4 \%$, but was $34.4 \%$ using the $97 / 8$-in. diameter bit. The rocks are moderately but pervasively altered with prominent dark halos next to fractures. The fractures are filled with four generations of vein-filling material: (1) Fe-Mn oxyhydroxides; (2) green clays; (3) Fe-Mn oxyhydroxides again; and (4) calcite/aragonite with minor green clays. These were followed by (5) general replacement of interstitial glass with pale yellow clays. The uppermost basalt in Hole 595A experienced only Stage 3-5. Extensive cross-cutting fractures were produced primarily just before or during each alteration stage. Stages 1-3 are probably related to nearaxis hydrothermal activity, involving $\mathrm{Fe}$ - and Mn-bearing solutions similar to those at eastern Pacific spreading centers. Stages 4 and 5 are related to crustal aging which sealed the crust, allowing successful drilling.

Following coring, the BIP was lowered to the seafloor, with its electromechanical (EM) cable attached, and then into the borehole following reentry. Prior to this, Melville had placed several oceanbottom seismographs (OBS) near the hole and completed two refraction runs and part of a third. The second ws a 10-km circle around Hole 595B using Glomar Challenger as a fixed reference. The objective was to determine the anisotropy of the upper crust. The BIP began recording shots part way through the first long refraction line.

The BIP was in Hole 595B sending seismic data up the EM cable from $1058 \mathrm{Z} 6 \mathrm{Feb} .1983$ to $1000 \mathrm{Z} 11 \mathrm{Feb}$. 1983. In this period, continuous tape recordings were made on deck. Both vertical and the east horizontal sensors in the BIP behaved normally, but the north horizontal sensor was always noisy and was essentially useless during the recording period. In all, 348 shots from 3 unre- versed refraction lines were recorded. The longest line was shot to $260 \mathrm{~km}$ at the limit of signal/noise for $300-\mathrm{lb}$. shots. The shot water waves were also recorded using a surface hydrophone suspended through the moon pool. Ambient noise is about 10 times the noise recorded at Site 395 during the previous deployment of the BIP on Leg 78B. Noise was sampled by the BIP (and by the OBS) during special time windows in which the ships screws and thrusters were stopped. Over 60 earthquakes were recorded. Most have S-P times in the ranges $16-18$ and $80-110 \mathrm{~s}$. The nearest events were unexpected and their sources unknown. Most other events are probably from the Tonga Trench, but seismic sources in the Cook and Society islands cannot be excluded.

Following completion of on-deck recording, the EM cable was attached to the bottom-processing package (BPP) of the MSS, which was then lowered to the seafloor. An installation recovery and reinstallation mooring (IRR), consisting of a riser cable, two sets of buoys separated by a grapnel line, and an anchor line, were deployed on a bearing of about $310^{\circ}$ from the hole. Finally, navigation beacons necessary to locate the mooring during retrieval operations were dropped to the seafloor. The entire system was in place for a planned 45 days of teleseismic recording.

In April 1983, Melville returned to the vicinity of Site 595 and retrieved the BPP. Unfortunately, a leak had partially flooded one of the capsules causing teleseismic recording to cease after only $40 \mathrm{hr}$. on the seafloor. However, additional on-deck recording at that time confirmed that the BIP was still functioning normally. A dummy BPP was lowered to the seafloor, but this can be retrieved and replaced with a functioning BPP at any time.

\section{INTRODUCTION}

This chapter summarizes the principal results of drilling at Deep Sea Drilling Project (DSDP) Site 595, where the Ngendei Seismic Experiment and the emplacement of DARPA's Marine Seismic System (MSS) were carried out. Background and objectives for this work are presented in the introductory chapter to this volume. Interpretation of the seismic experiment and drilling results are presented in subsequent parts of this volume. The chapter also provides a detailed operational summary of the successful deployment of the MSS during Leg 91 .

\section{SITE SELECTION}

Melville arrived in the region of the proposed drill site approximately $30 \mathrm{hr}$. before Glomar Challenger. This schedule had been pre-arranged to allow the scientific party on Melville enough time to choose an optimum location for drilling prior to the arrival of Glomar Challenger. The area had been chosen because of its proximity to the Tonga Trench (approximately $900 \mathrm{~km}$ distant), but no detailed surveys had been carried our prior to Melville's (Fig. 1). The instruments used in the experiments had to be close enough to the trench to record the numerous earthquakes associated with the Tonga seismic zone, and at the same time be far enough away for rays to sample the major discontinuities in the mantle.

A survey was made in the area using Melville's digital recording single-channel water-gun system (see Kim et al., this volume). Final site selection was based on several criteria: (1) Approximately $100 \mathrm{~m}$ of sediments are needed to spud in a drill string and place a reentry cone on the seafloor; (2) water depth should be as shallow as possible to avoid undue torque on the drill string; and (3) interpretation of seismic refraction data is less complicated in an area of low topographic relief. A "reverberant layer" predicted for the region by Houtz and Ludwig (1979) was found to be absent very early in the 


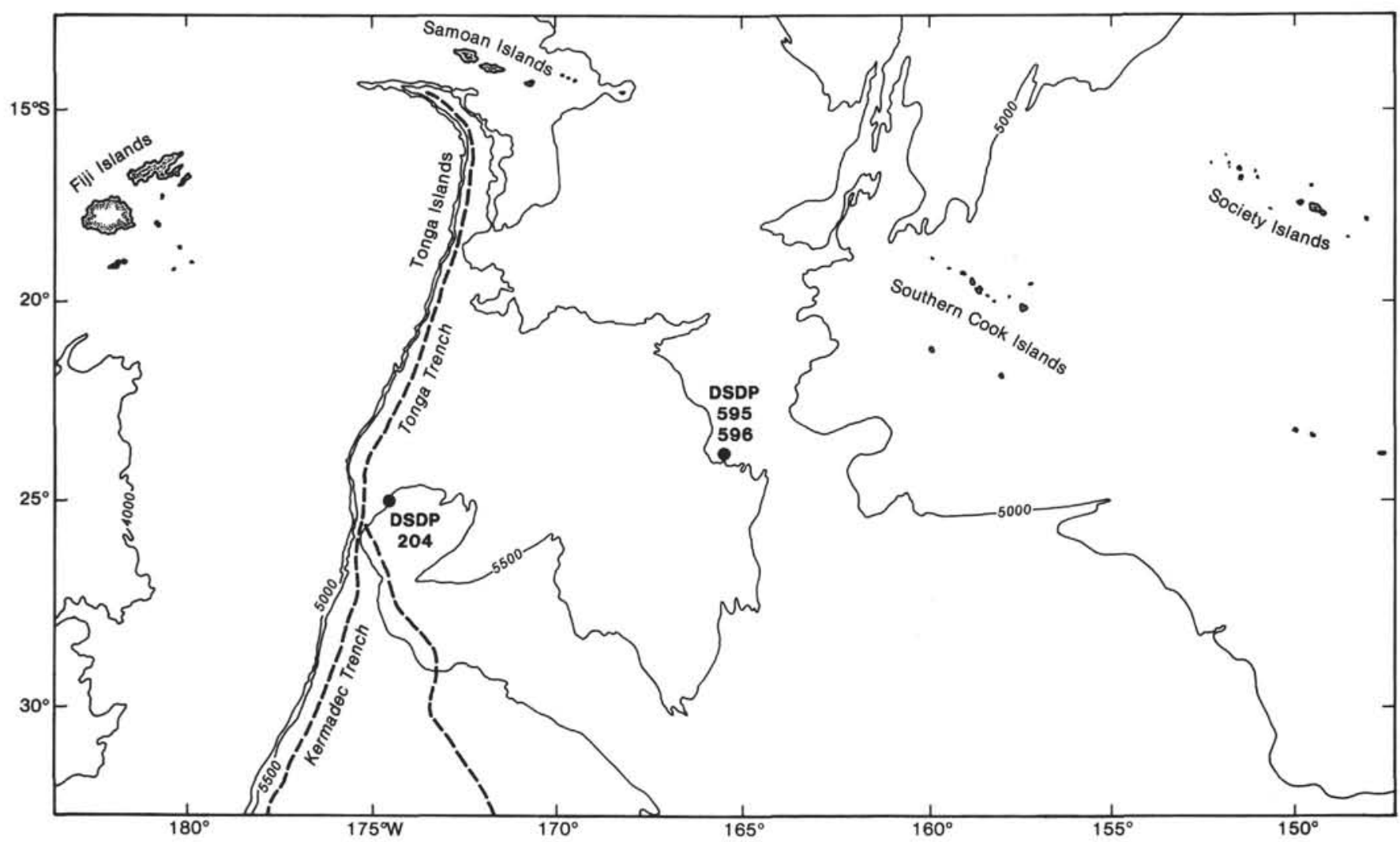

Figure 1. Location of Sites 595 and 596 with respect to the Tonga Trench and the nearest island groups in the southwest Pacific. Also shown in Site 204, the only other DSDP hole on the Pacific plate in this region. This diagram depicts the essential information used for the Leg 91 site selection, although profiler records from Houtz and Ludwig (1979) and from surveys in 1969 by Eltanin and 1972 by Conrad (the latter operated by Lamont-Doherty Geological Survey) were used to ensure that sufficient sediments and no seamounts were in the area selected. Several backup targets (not used, thus not shown) were also selected from the profiler records.

surveying program, and we attributed the presence of the layer to the use of a low-frequency air-gun source with a narrow recording band width.

The Melville party identified what they believed to be the optimum drill site: an area of maximum sediment thickness at a water depth of approximately $5600 \mathrm{~m}$ in an area of low relief. The sediment thickness was thinner than desirable, probably less than $100 \mathrm{~m}$, but this was felt to be adequate. As Glomar Challenger approached this site, its air-gun profiling system, operating at substantially higher frequencies, was recording sediment thicknesses much thinner than those detected by the Melville's water gun. Glomar Challenger agreed to the site selection after receiving assurances from $\mathrm{Mel}$ ville that the sediments were sufficiently thick. The shallow reflection tracked by Glomar Challenger was later found to be the transition to chert-bearing sediments.

\section{DRILLING OPERATIONS}

\section{Wellington to Site $\mathbf{5 9 5}$}

Leg 91 began at $0943 \mathrm{hr}$, 9 January, with the first mooring line put over to the fueling pier in Wellington Harbor, New Zealand.

At $0812 \mathrm{hr}$., 16 January, the last line was cast off in Wellington, and the vessel departed for survey area MSST-5. Winds were gusting as high as 60 knots, but decreased through the morning as Glomar Challenger cleared the approaches to Wellington Harbor and stopped briefly to test the thrusters and dynamic positioning system. The ship then exited Cook Strait and turned northeastward along the coast of North Island.

The windy and choppy conditions gradually diminished during the northeastward voyage into subtropical waters. With good weather prevailing, an excellent average speed of 9.9 knots was made good over the 1480-mi. transit.

Survey area MSST-5 (standing for Marine Seismic System-Tonga) was located about $350 \mathrm{mi}$. west-southwest of Rarotonga Island and about $500 \mathrm{mi}$. east of the Tonga Trench.

Daily communication was maintained with Melville, which was en route to the joint operating area from the north. Melville arrived at MSST-5 about $30 \mathrm{hr}$. before Glomar Challenger and began profiling the region in search of the optimum drill site. An area of maximum transparent sediment thickness was identified by $\mathrm{Mel}$ ville, which stood to the west of the originally anticipated target about $1 \mathrm{n}$. mi. as Glomar Challenger approached at 6 knots on a heading of $047^{\circ}$. Glomar Challenger passed slightly west of the preferred target, then changed course to starboard $180^{\circ}$. She passed closer to the projected target this time, but the transparent sediment did not appear to match that described by Melville. Presuming that this was because we were recording the reflection data using different filter settings than $\mathrm{Mel}$ - 
ville, we decided to drop the beacon anyway on one final pass over the target after turning to port to $000^{\circ}$. We launched the positioning beacon finally at $1700 \mathrm{hr}$., 21 January.

\section{Hole 595}

The initial pipe trip was slowed for measuring pipe and for removing three unsatisfactory joints of pipe from the drill string. The precision depth recorder (PDR) indicated a water depth of $5606 \mathrm{~m}$ from the rig floor. Since Hole 595 was to be an exploratory hole for a reentry site, an accurate water depth determination was essential. The power sub was deployed and the core bit was lowered to $5614 \mathrm{~m}$. When the inner core barrel was recovered, the core catcher contained only a handful of manganese nodules and traces of clay. This occurred while a party from Melville had ventured to Glomar Challeng$e r$ for an initial evaluation of site survey data. Since the sediment apparently had washed out of the barrel, a second punch core attempt was made, with the bit lowered only to $5613 \mathrm{~m}$. This time the barrel was retrieved completely clean, and water depth was set at $5613.5 \mathrm{~m}$.

A jet-in test was then made to determine the maximum depth to which 16-in. conductor casing could be set. The seafloor sediment was found to be soft clay which was penetrated easily with a low circulation rate. A quite firm stratum was encountered at only $33 \mathrm{~m} \mathrm{BSF}$, however, and neither increased weight nor circulation resulted in further progress.

We considered this to be insufficient soft sediment to support the reentry cone and casing system or to provide lateral support for the bottom-hole assembly (BHA) during the drilling of hard material, and therefore we decided to find a more suitable location. Satellite navigation (SAT NAV) fixes received on site and further consultation with Melville indicated that the positioning beacon was located near the edge of the area identified by $\mathrm{Mel}$ ville, and that somewhat thicker soft sediments lay to the east of Glomar Challenger within offsetting range of the dynamic positioning system. We pulled the bit clear of the seafloor at $1000 \mathrm{hr}$., 22 January.

\section{Hole 595A}

We offset the vessel $457 \mathrm{~m}$ east and $15 \mathrm{~m}$ north (Fig. 2). The new PDR depth was $5624 \mathrm{~m}$, and the bit was lowered to $5631.8 \mathrm{~m}$ for a seafloor punch core. Core recovery was $2.7 \mathrm{~m}$ and water depth was established at $5629 \mathrm{~m}$.

Again the casing jet-in test found extremely soft sediment, but the thickness had increased by only $3 \mathrm{~m}$ and the bit was stopped at $36 \mathrm{~m}$ BSF. We then cored continuously from the seafloor. Coring data are presented in Table 1 . The first $36 \mathrm{mn}$ consisted of soft brown pelagic clay. The hard stratum was found to be porcellanite and chert. This was interbedded with brown clay for an additional $32 \mathrm{~m}$, and typically poor core recovery was achieved through this interval of alternating hard and soft material. Igneous rock was encountered at only $70 \mathrm{~m}$ BSF. This presented a difficulty, as about $100 \mathrm{~m}$ of sediment are required to provide lateral support for the BHA for safe and efficient drilling operations. Coring contin-

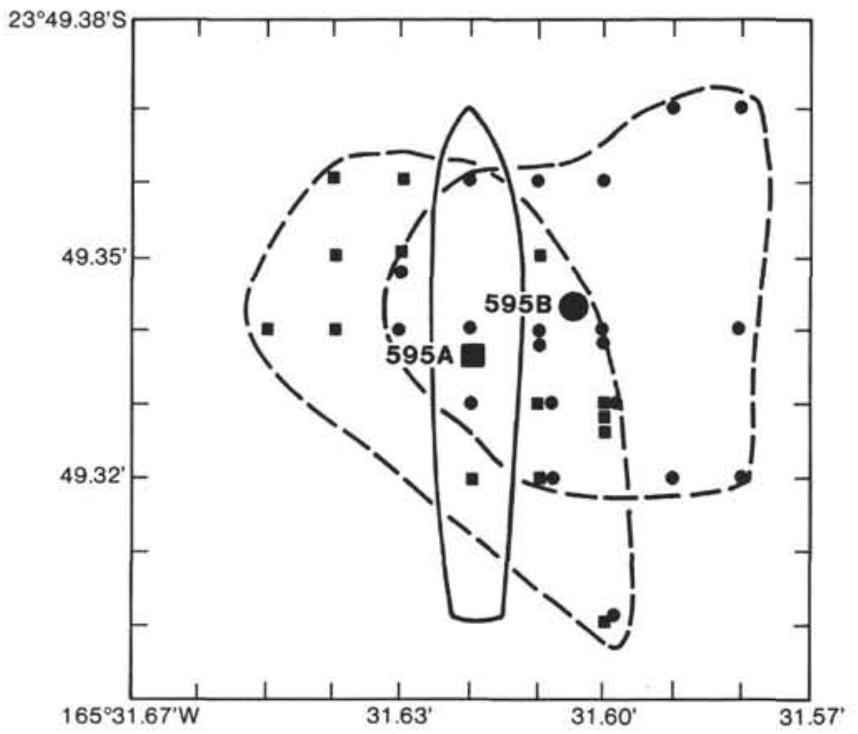

Figure 2. High-quality satellite navigation fixes compiled during the occupation of Holes 595A and 595B, showing mean locations for each hole and the dimensions of Glomar Challenger (122 m long) for scale. The scatter of fixes reflects the intrinsic accuracy of the satellite-navigation system and some drift of the vessel over each hole. Fourteen fixes were used to compile the mean site location for Hole 595A, and nineteen fixes were used for Hole 595B.

Table 1. Coring summary, Site 595.

\begin{tabular}{rccccccc}
\hline $\begin{array}{c}\text { Core } \\
\text { no. }{ }^{\mathrm{a}}\end{array}$ & $\begin{array}{c}\text { Date } \\
\text { (Jan. } \\
1983)\end{array}$ & Time & $\begin{array}{c}\text { Depth from } \\
\text { drill floor } \\
(\mathrm{m})\end{array}$ & $\begin{array}{c}\text { Depth below } \\
\text { seafloor } \\
(\mathrm{m})\end{array}$ & $\begin{array}{c}\text { Length } \\
\text { cored } \\
(\mathrm{m})\end{array}$ & $\begin{array}{c}\text { Length } \\
\text { recovered } \\
(\mathrm{m})\end{array}$ & $\begin{array}{c}\text { Amount } \\
\text { recovered } \\
(\%)\end{array}$ \\
\hline Hoie 595 & & & & & & \\
1 & 22 & 0733 & $5613.5-5614.0$ & $0.0-0.5$ & 0.5 & 0.1 & 20 \\
H1 & 22 & 1101 & $5614.0-5646.0$ & $0.5-32.5$ & $\frac{-}{0.5}$ & $\frac{-}{0.1}$ & $\frac{-}{20}$
\end{tabular}

Hole 595A

$\begin{array}{rllll}1 & 22 & 1423 & 5629.0-5631.8 & 0.0-2.8 \\ \mathrm{~S} 1 & 22 & 1630 & 5631.8-5641.2 & 2.8-37.0 \\ 2 & 22 & 1826 & 5631.8-5641.2 & 2.8-12.2 \\ 3 & 22 & 1945 & 5641.2-5650.8 & 12.2-21.8 \\ 4 & 22 & 2121 & 5650.8-5660.4 & 21.8-31.4 \\ 5 & 22 & 2325 & 5660.4-5667.0 & 31.4-38.0 \\ 6 & 22 & 0115 & 5567.0-5671.0 & 38.0-42.0 \\ 7 & 23 & 0322 & 5671.0-5679.6 & 47.0-50.6 \\ 8 & 23 & 0540 & 5679.6-5689.2 & 50.6-60.2 \\ 9 & 23 & 0725 & 5689.2-5698.8 & 60.2-69.8 \\ 10 & 23 & 1219 & 5698.8-5708.4 & 69.8-79.4 \\ 11 & 23 & 1605 & 5708.4-5713.4 & 79.4-84.4 \\ 12 & 23 & 1927 & 5713.4-5717.5 & 84.4-88.5\end{array}$

\begin{tabular}{rrr}
2.8 & 2.69 & 96.1 \\
$\overline{9.4}$ & $\overline{6.28}$ & -66.8 \\
9.6 & 4.79 & 49.9 \\
9.6 & 6.36 & 66.3 \\
6.6 & 2.08 & 31.5 \\
4.0 & 0.19 & 4.8 \\
8.6 & 0.61 & 7.1 \\
9.6 & 4.29 & 44.7 \\
9.6 & 0.95 & 9.9 \\
9.6 & 3.79 & 39.5 \\
5.0 & 3.64 & 72.8 \\
4.1 & 1.80 & 43.9 \\
\hline 88.5 & 37.47 & 42.3 \\
18.7 & 9.23 & 49.4 \\
69.8 & 28.24 & 40.5
\end{tabular}

Hole 595B

\begin{tabular}{|c|c|c|c|}
\hline \multicolumn{3}{|c|}{ Drilled } & $5630.0-5664.0$ \\
\hline H1 & 25 & 1415 & $5664.0-5696.9$ \\
\hline 1 & 25 & 1945 & $5695.9-5703.0$ \\
\hline 2 & 26 & 0305 & $5703.0-5711.5$ \\
\hline 3 & 29 & 1758 & $5711.5-5717.4$ \\
\hline 4 & 30 & 0252 & $5717.4-5726.5$ \\
\hline 5 & 30 & 0830 & $5726.5-5735.6$ \\
\hline 6 & 30 & 1200 & $5735.6-5744.7$ \\
\hline 7 & 30 & 1744 & $5744.7-5753.8$ \\
\hline
\end{tabular}

$0.0-34.0$
$34.0-65.9$
$65.9-73.0$
$73.0-81.5$
$81.5-87.4$
$87.4-96.5$
$96.5-105.6$
$105.6-114.7$
$114.7-123.8$

\begin{tabular}{rcr}
$\bar{Z}$ & $\bar{y}$ & - \\
$\overline{7.1}$ & $\overline{0.07}$ & $\overline{1.0}$ \\
8.5 & 1.80 & 21.2 \\
5.9 & 2.32 & 39.3 \\
9.1 & 4.04 & 44.4 \\
9.1 & 2.50 & 27.5 \\
9.1 & 2.51 & 27.6 \\
9.1 & 3.16 & $\underline{34.7}$ \\
\hline 57.9 & 16.40 & 28.3 \\
54.8 & 16.40 & 29.9 \\
3.1 & 0.0 & 0.0
\end{tabular}

Note: - means not measured.

${ }^{\mathrm{a}} \mathrm{H}=\mathrm{a}$ wash core; i.e., a core taken while washing ahead for an interval larger than $9.5 \mathrm{~m}$, but without the center bit in place. $\mathrm{S}=$ a side-wall core; i.e., a core taken in the side of the hole. 
ued in basement lavas to a total depth of $5717.5 \mathrm{~m}, 88.5 \mathrm{~m}$ BSF. The basement rocks were found to be favorable for the seismic instrument implantation except that rubbly material from the upper few meters of lava was falling into the hole, resulting in bottom fill between cores. This indicated the need for surface casing through the entire sediment column when the reentry installation was made.

With all the objectives of the exploratory hole achieved, we recovered the drill, and the bit arrived on deck at $0857 \mathrm{hr}$., 24 January. The BHA was given a magnaflux inspection in view of the pounding endured during the shallow hard rock drilling, and the bumper subs were replaced.

\section{Hole 595B}

Further review of the now extensive profiling accomplished by Melville failed to disclose a location more favorable than the immediate vicinity around Hole 595A for drilling. We thus decided to emplace the MSS at Site 595 despite the unfavorable drilling conditions, rather than move to a distant and less desirable contingency site. Design of a dual casing reentry installation was then undertaken.

The reentry cone, which had been assembled in Wellington and secured on the port side main deck bulwark, was keelhauled and hung off below the vessel's moon pool. An abbreviated conductor casing string was then assembled using three joints of 16 -in., 75 -lb., range 2 casing and a cutoff "pup" shoe joint designed to place the casing shoe just $34 \mathrm{~m}$ below the seafloor. A BHA of drill collars and the casing running tool was spaced to place the $147 / 8$-in. core bit at the casing shoe. The BHA was latched, first into the casing hanger and then into the reentry cone as bumper subs and more drill collars were added. The cone slings were then removed and the drill string was run toward the seafloor.

The first half of the pipe trip was smooth until surge caused the vessel to heave, and the submerged casingcone assembly to buoy upward around the drill string with the passing of each surge. This caused the bumper subs above the cone to close partially and then open with hammer blows that jarred the entire vessel, disturbing light sleepers. This condition became worse as the trip progressed, apparently as the vertical elasticity of the long drill string contributed to the surge dynamics.

Hole 595B was spudded at $0524 \mathrm{hr}$., 25 January. The location of the hole and that of Hole 595A is shown in Figure 2. The casing was jetted in easily at a low circulation rate, and the mud skirt stopped at $5630 \mathrm{~m}$ below the derrick floor. An expendable $12-\mathrm{kHz}$ pinger attached to the skirt gave an altered pulse repetition rate at this time and then died, indicating contact with the seafloor. A shifting tool was then run on the sand line and the coring-cone assembly was released without difficulty.

The $147 / 8$-in. hole was then drilled through most of the chert-clay interval (which began only $2 \mathrm{~m}$ below the casing shoe) to $66 \mathrm{~m}$ BSF before coring began. Hard drilling was encountered at $64 \mathrm{~m}$. Unfortunately the first core failed to recover the lowermost sediments, which had been poorly recovered in Hole 595A and only one chunk of the uppermost basaltic rock unit was retrieved- jammed into the core catcher. The second core took the large-diameter hole to a total depth of $81.5 \mathrm{~m} \mathrm{BSF}$, with $1.8 \mathrm{~m}$ of core recovered. The bit was then pulled into the casing and run back to total depth as a "wiper trip." $\mathrm{Al}$ though no fill was "felt," a mud flush was circulated to ensure the cleanest possible hole for setting casing. A round trip of the drill string was then begun for the $113 / 4$ in. casing string.

\section{First Reentry-Surface Casing}

Eight joints of range two, 113/4-in., 54-lb., grade K-55 casing were made up to the reentry casing hanger and hung off in the rig's moon pool. A special BHA of drill pipe and bumper subs was then assembled below the threaded casing running tool, which was screwed into the casing hanger to engage the casing string.

The drill string was run to place the casing shoe $7 \mathrm{~m}$ above the reentry cone. When the logging sheaves and cable had been rigged, the reentry sonar tool was attached. The tool began to malfunction during the rigfloor check, which is the final test before lowering through the pipe. A backup sonar tool was then deployed, resulting in a 3/4-hr. delay, and started down the drill pipe. This wireline trip was extended by an additional $2 \mathrm{hr}$. when it was necessary to repair a leaking oil line on the transmission of the logging winch. Sonar scanning began at $1230 \mathrm{hr}$., 27 January, and the reentry cone was found to be almost directly beneath the casing shoe. The casing was lowered an additional $2 \mathrm{~m}$, based on sonar range to the seafloor, and it was necessary only to wait a few more minutes before the drill string swung back over the cone. No ship movements were necessary, and a successful reentry stab was made after only $14 \mathrm{~min}$. of scanning.

The sonar was recovered and an additional stand of drill pipe was added to verify the reentry. When the casing had been run into the hole, a bridge or hole fill was encountered about $3 \mathrm{~m}$ above the setting depth of $74 \mathrm{~m}$ BSF, but the shoe was circulated into place without difficulty. The casing was landed in the reentry cone and latching was checked by picking up on the string and noting the weight gain. The casing string was released by setting its weight onto the reentry cone and then rotating the drill string to the right with the power sub.

Cementing lines were then rigged and 70 sacks of neat grade $\mathrm{G}$ cement were mixed to $15 \mathrm{lb} . / \mathrm{gal}$. slurry and pumped into the drill pipe. An aluminum latch-down top plug was launched and followed by an additional 4 barrels of slurry and 10 barrels of fresh water. The cement was displaced with seawater until the plug landed at the shoe at $1740 \mathrm{hr}$., 27 January. The round trip for a coring BHA began immediately.

\section{Second Reentry: 97/8-in. Core Bit}

The initial reentry sonar tool again failed-this time after it had been run $1800 \mathrm{~m}$ down the pipe. After a $21 / 2$ hr. delay, the backup unit was lowered to the bit and scanning began.

Vertical motion of the core bit, resulting from vessel heave in 4-ft. swells and from the amplification of a 5.5-km drill string, was about $3 \mathrm{~m}$ total amplitude. The 
surge effect occasionally caused the sonar tool to float up and then to slam down upon the lower support bearing during the scanning phase of the operation despite downward pressure applied with the rig pump. Although the reentry cone was originally acquired at close range and the pipe had swung close over the cone on several occasions, we still could not achieve a centered target after 3-3/4 hr. At this point, the repeated pounding finally caused an electronic failure within the tool and it had to be retrieved. On recovery, we found that the lowermost portion of the logging cable also had been damaged by the vertical cycling. About $100 \mathrm{~m}$ of line was cut off and the cable was reheaded. Scanning recommenced when the replacement sonar had been landed at the bit. A proper target presentation was finally seen after an additional $21 / 4 \mathrm{hr}$. of scanning and maneuvering, and the reentry was made at $0623 \mathrm{hr}$., 29 January.

When the sonar had been retrieved and the reentry had been verified, an inner core barrel equipped with a center bit was pumped into place. The power sub was then deployed and used to drill out about $8 \mathrm{~m}$ of cement, the latch-down plug, and the casing shoe. The hole beneath the shoe was found to be open to total depth, and the center bit was tripped for a standard inner core barrel.

Coring then resumed in basalt. The coring operation was tedious since there was not yet adequate support for the BHA, hence there was great risk of losing the entire installation. A considerably increased drilling rate through the interval of about 105-115 m BSF was welcomed at first, but was soon found to be the result of intensely fractured basalt. The subsequent core encountered harder drilling, but hole cleaning problems had already begunapparently originating in the fractured interval above. Two meters of hard fill accumulated during the sand line trip for Core 7.

Risks of continued penetration were assessed at this point. Chances of the drill string's becoming stuck, although only slight to moderate, were considered to be real. Since sufficient open hole had been made in basement rocks for the seismic instrument implantation, the scientific benefits of further penetration were foregone and coring was terminated at a total depth of $5753.8 \mathrm{~m}$ (123.8 m BSF).

A 40-barrel weighted mud flush was circulated to clear as much detritus from the hole as possible. The bit was pulled above the casing shoe and then run back to total depth. The hole was clean all the way. The string was then pulled, with the well-worn core bit arriving on deck at $0445 \mathrm{hr}$., 31 January.

Accrued ton-miles dictated that the rig's drilling line be changed before the beginning of the next pipe trip. Time and working-space considerations prompted the decision to move the rig off site and dispose of the line before beginning the MSS deployment. When the new line had been strung, the vessel was moved $16 \mathrm{~km}$ northeast of the site and the $1800-\mathrm{ft}$. line was jettisoned from the drawworks drum. The ship then returned to within range of the positioning beacon, where a 45 -min. drift test was conducted with the vessel dead in the water to aid in projecting the effect of local wind and current forces on the planned deployment of MSS ropes and cables. The ship then resumed positioning over the reentry cone after a total operational hiatus of $71 / 4 \mathrm{hr}$.

\section{Third Reentry: MSS Reentry Sub}

The lowermost (stinger) portion of the MSS reentry assembly was moved to the rig floor and the cable was keelhauled over the side and up through the moon pool. Assembly of the reentry sub, together with testing and installation of the BIP consumed $11 \mathrm{hr}$. About half of this time was spent dealing with minor, although timeconsuming, mechanical problems.

A reentry sonar tool was then attached to the sonar sinker bar and the entire assembly was lowered into the assembled reentry sub for a final check of clearances and vertical spacing. About $20 \mathrm{~cm}$ was added to the sonar assembly to assure adequate protrusion of the transducer below the stinger. The step of rigging the logging sheaves and attaching the logging cable was deleted, although later regretted, in the interest of saving time.

The upper portion of the BHA was then made up and the pipe trip begun. The procedure entailed lowering pipe while simultaneously paying out the EM cable (which was attached to the stinger from beneath the ship) using the cable (Pengo) winch on the port side of the main deck. Problems with the electrical signals from the BIP began almost immediately, however, and the pipe trip was halted after only six stands had been run.

The malfunction turned out to be a serious one that was ultimately traced to damaged cable in the uppermost (cable isolator) section of the BIP. The mechanical damage had permitted water to enter the cable, which thwarted attempts to make an acceptable electrical retermination. The cable isolator was modified to remove the cause of the cable damage and the EM cable had to be reheaded completely, both electrically and mechanically, a process which took $2 \frac{1}{2}$ days.

While this process was occurring, the weather deteriorated to conditions that were marginal for handling the BIP and the drill string, but prohibitive for reentry operations. We therefore waited an additional $17 \mathrm{hr}$. while wind and swell abated.

Trip preparations went more smoothly the second time. Lowering pipe and cable together could be done at about half the rate of a normal pipe trip. A routine was quickly developed for orienting the pipe and feeding out cable, but interruptions for repairs to the Pengo winch totaled $5 \mathrm{hr}$. The stinger reached reentry depth at $0830 \mathrm{hr}$., 5 February.

The logging sheaves were rigged and the sonar/sinker bar assembly made up with difficulty. The sonar tool then failed almost immediately on the rig-floor test. The electronics package was replaced, but this did not solve the problem. Upon dismantling the entire assembly, the conductors were found to have twisted off in the logging cable head during final attachment to the pipe sinker bars. The cable was reheaded and the long apparatus reassembled, with care taken to protect the cable head. The sonar functioned normally as it started down the pipe, but it had stopped receiving by the check at $1500 \mathrm{~m}$. On retrieval, more wires were again found to 
have broken at the cable head. While the cable was being reheaded once more, the spring centralizer of the sinker bar assembly was modified to permit free rotation and detorquing of the logging cable.

Sonar function was normal on the third lowering, after a 9-hr. delay, and the sonar seated properly in the reentry sub. After $76 \mathrm{~min}$. of scanning and maneuvering, a smooth and gentle reentry was made at $2128 \mathrm{hr}$. The drill string was lowered cautiously for the final few meters to seat the stinger and to actuate two bumper subs.

The bumper subs were used to decouple vessel heave motion while the sonar tool was recovered and while a Baker equalizing valve was pumped into place at the top of the reentry sub assembly. The rig mud pump was then used to pressure the pipe to $2500 \mathrm{psi}$. This actuated the hydraulic system of the BIP carriage to shear the restraining pins and move the BIP into release position above the bore of the stinger. A sudden weight gain was noted on the EM cable as the BIP was released into the stinger.

The BIP was lowered through the upper (cased) hole and into open hole. By cable measurement, it came to rest about $20 \mathrm{~m}$ short of total depth. This could not be verified because of the great cable length and doubts as to the accuracy of the winch depthometer, but was recorded simultaneously on the tensiometer recording in the Teledyne van. All parties were satisfied that the BIP had been emplaced in open hole in igneous rock, and drill string recovery was initiated.

The vessel was offset $60 \mathrm{~m}$ southeast (up-current) and the pipe was pressured to about 3700 psi with the cementing pump to open the gate in the stinger for release of the cable. The reentry sub was then pulled clear of the reentry cone. The cable weight indicator showed no effect of the pipe movement-an indication that separation of cable and pipe had been accomplished. The positioning offset was increased to $150 \mathrm{~m}$ in the same direction, and four "wet" stands of drill pipe were pulled before the equalizing valve was recovered with the sand line and overshot. The ensuing pipe trip was routine, but as the reentry sub assembly came into view, we saw that the stinger was missing. All ten attachment bolts remained hanging in the flange at the base of the BIP carriage. All the bolts showed virtually identical tensional failures in the threaded portion. Opinions differed as to whether the stinger had been left in the reentry cone, or had fallen from the carriage into the mud beside the cone during the pipe trip.

\section{Refraction Experiment and IRR Deployment}

Glomar Challenger then held position, recording seismic refraction shots through the BIP until Melville completed the shot line then in progress. The offsets were then changed to place the vessel about $75 \mathrm{~m}$ south of the reentry cone, where a transponder for an acoustic transponder navigation (ATNAV) system was launched. The EM cable was then slowly paid out as the ship was offset to a position about $1420 \mathrm{~m}$ bearing $310^{\circ} \mathrm{T}$ from the cone. About $850 \mathrm{~m}$ of EM cable remained on the winch at this time.
Glomar Challenger remained at this station, recording earthquakes and explosions on deck for 4 additional days. The BIP was constantly monitored with shipboard recording equipment connected directly to the EM cable. Periods of coordinated refraction shooting by $\mathrm{Mel}$ ville were alternated with long intervals of passive recording of teleseismic events (earthquakes). At several times Glomar Challenger's thrusters were silenced to allow recording of ambient noise. A small boat rendezvous was made for a brief personnel exchange between the two ships for planning purposes. A $13.5-\mathrm{kHz}$ positioning beacon was sent to Melville and was subsequently launched about $1500 \mathrm{~m}$ northwest of Glomar Challenger's position on the afternoon of 9 February.

At $1300 \mathrm{hr}$, 10 February, the initial steps of the IRR system deployment were begun. The vessel was offset an additional $280 \mathrm{~m}$ west (to the maximum north and west offsets possible) while the EM cable was paid out to the safe minimum on the winch drum. The winch was modified for the IRR phase, the BPP was moved by crane into position on the main deck, and the EM cable tension was transferred from the winch to the ship's structure by means of a cable grip.

The EM cable was disconnected from the shipboard recording instruments early on 11 February and made up to the BPP for final electronic checks. At this time, some of the vital BIP functions could not be recorded or interfaced with the BPP. Troubleshooting placed the malfunction in the interfacing circuitry within the BIP. Nothing could be done to remedy the situation short of recovering the BIP. This would have required several additional days, and once again placed the equipment at high risk during reentry. After considerable discussion, we decided that the system was still providing sufficient information to provide adequate recording of teleseisms, hence we would continue the deployment with the system not fully operational.

With only light breezes and very little swell, the final, critical phases of the deployment were undertaken. The BPP, which weighs over 4 tons in air, was lifted over the side by the ship's crane. The precarious operations of first transferring the weight of the EM cable to the BPP and then the entire weight to the IRR isolation cable on the Pengo winch were accomplished with only minor difficulties. The BPP had lowered into the water at $1400 \mathrm{hr}$., 11 February.

After only a few minutes of paying out the $11 / 8$-in. steel isolation cable, problems with the Pengo winch made it necessary to shut down for $3 \mathrm{hr}$. for modifications and repairs to the winch. During this time there was some interference with the state-of-health acoustic telemetering beacon by the ship's dynamic positioning system, as the BPP was hanging close beneath the vessel.

When the $450-\mathrm{m}$ isolation cable had been paid out, a controlled vessel drift to the northwest was resumed as the $13 / 4-$ in. power braid riser cable was deployed. Within minutes, Glomar Challenger was able to switch to automatic positioning and controlled offsetting of the 13.5$\mathrm{kHz}$ beacon placed by Melville. The BPP had landed on the seafloor when the vessel had passed over the beacon 
and moved about $500 \mathrm{~m}$ to the northwest. Again the winch depthometer reading was considerably short as compared with the concurrent readings of the ship's PDR and the ATNAV transponder attached to the BPP.

The riser leg payout continued, with frequent stops for winch repairs. Maximum north and west positioning offsets were reached, and a controlled drift continued in the semiautomatic mode. The deployment was complicated somewhat when the riser line was found to be nearly $1 \mathrm{~km}$ longer than specified. Over $7 \mathrm{~km}$ of the heavy braid had been paid out when the beginning of the $7 / 8$-in. grapnel leg braid was reached and the " $\mathrm{A}$ " crown buoy was attached. As payout of the 3-km grapnel leg began, the vessel moved out of range of the positioning beacon and rate of drift was controlled in semiautomatic mode by monitoring tension on the line. When the "B" crown buoys at the anchor end of the grapnel leg had been launched, a $16-\mathrm{kHz}$ beacon was dropped to aid in fixing the position of the IRR acoustic release and in deploying the anchor leg. The beacon failed within minutes after launch and was replaced by a $13.5-\mathrm{kHz}$ unit. The acoustic release/ATNAV transponder link assembly was put over and deployment of the 3-km anchor leg began while the beacon was falling. Unfortunately the beacon signal first weakened, then became distorted and unusable approximately $1 \mathrm{hr}$. after launch-probably on landing at the seafloor. The teamwork of pilothouse and winch personnel, together with excellent weather, allowed the deployment to be completed without loss of control. The end of the anchor line was removed from the winch and attached to the anchor. When the slow, controlled drift of the vessel had produced the proper tension in the IRR, the anchor was released at $0858 \mathrm{hr}$., 12 February.

Melville had been standing by to observe and report submergence of the crown buoys before departing for her scheduled port call in Tahiti. After a tension-charged wait around the radio, Glomar Challenger heard the report that the final "B" crown buoy had disappeared at $0948 \mathrm{hr}$. As Melville steamed away, Glomar Challenger returned to the "B" crown buoy area and began a search while interrogating the ATNAV transponder. The minimum range to the transponder recorded during the 2-hr. search was about $900 \mathrm{~m}$, verifying the success of the deployment.

The vessel then returned to the area of the BPP for the final task of placing ATNAV transducers on either side of the BPP to be used in its recovery by Melville. This proved to be much more difficult and time consuming than had been anticipated. The ATNAV transponder on the BPP was to be used as a reference in positioning to launch the other transponders, but thrusters and other ship's noise made effective communication with the transponder impossible in the $5600-\mathrm{m}$ water depth. Using semiautomatic dynamic positioning on a distant, intermittent beacon, transponders were finally emplaced in the approximate positions of $2750 \mathrm{~m}$ from the BPP on bearings of $017^{\circ}$ and $251^{\circ} \mathrm{T}$. At $1700 \mathrm{hr}$., 12 February, DARPA operations for Leg 91 had been successfully completed, and the ship was moved to Site 596 for continued coring operations.

\section{SEDIMENT LITHOLOGY}

At Site 595, sediments were cored in Holes 595 and $595 \mathrm{~A}$. Hole 595 consists of a mud-line core and a $32-\mathrm{m}$ wash core. The mud-line core contains several Fe-Mn nodules smeared with brown (7.5YR 5/4) pelagic clay. The nodules are 1 to $3 \mathrm{~cm}$ in diameter and have a thin outer crenulated surface layer over a smoother inner layer. The few nodules cut open appear to have nucleated on sand-sized, manganese-crusted grains of pelagic clay. A mixture of $\mathrm{Fe}-\mathrm{Mn}$ nodules and brown pelagic clay was recovered in the core catcher of the wash core.

At Hole 595A, $69.8 \mathrm{~m}$ of sediment were cored, with $40.5 \%$ recovery. All sediments are intensely disturbed by the rotary coring process, obscuring bedding or other structures they may have had. Inasmuch as a nearly equivalent section was recovered with much less disturbance using the hydraulic piston corer at nearby Site 596, the reference lithologic summary for both Site 595 and 596 is given in the Site 596 report. Here, we divide the sediment column into two provisional and informal lithologic types, termed " $\mathrm{A}$ " and " $\mathrm{B}$," which were cored in descending stratigraphic order. These are distinguished only by the occurrence of porcellanite and chert interbedded with pelagic clay in the latter sediment type.

The two sediment types are described below, but bear in mind that the sediment stratigraphy at Site $\mathbf{5 9 5}$ is superseded by that at Site 596 .

\section{Type "A": Zeolitic Pelagic Clay}

From the mud line to $31.4 \mathrm{~m}$ below the seafloor, dark reddish brown (5YR 1/3) clays with minor blebs of yellowish brown (10YR 5/4) clays were recovered in cores marked by intense sediment disturbance. The pigment in the darker sediments, as observed in smear slides, consists of substances originally described during DSDP Leg 34 as RSOs (Red Semi-opaque Oxides; Quilty et al., 1973; Bass, 1973). These typically are largely X-ray amorphous, and probably consist of $\mathrm{Fe}$ - and $\mathrm{Mn}$-rich oxyhydroxides in cryptocrystalline form. Here, their existence is inferred from the color of the sediment, an abundance of reddish, nearly opaque, and extremely fine-grained material in smear slides, and of indurated Fe-Mn micronodules in coarse fractions.

Type " $A$ " sediments are dark reddish brown (5Y 3/3) with minor streaks or blebs of yellowish brown (10YR 5/4) sediment. In Hole 596, small beds of similar yellowish brown color were recovered using the hydraulic piston corer and are probably the undisturbed equivalents of the yellowish brown blebs here. RSOs are absent from smear slides of this material, except where introduced by coring disturbance.

Variation ranges of sediment components as estimated from smear slides are given in Table 2 . The ranges include sediments having both abundant and minor RSO contents. Proportions of components estimated from smear slides are shown in Figure 3, but sediment disturbance is sufficiently extreme that only broad trends may be inferred with any confidence. We note chiefly the abrupt (and antithetical) fluctuations in the proportions 
Table 2. Estimated smear-slide proportions of sediment components in Holes 595 and 595A

\begin{tabular}{lcc}
\hline & \multicolumn{2}{c}{$\begin{array}{c}\text { Sediment type } \\
\text { C\%) }\end{array}$} \\
\cline { 2 - 3 } \multicolumn{1}{c}{ Component } & "A" & "B" \\
\hline Silt-sized fraction & $2-30$ & $3-15$ \\
Clay-sized fraction & $70-100$ & $85-97$ \\
Clay minerals & $20-45$ & $35-45$ \\
Feldspars & None & $0-5$ \\
RSOs & $17-50$ & $25-33$ \\
Opaque micronodules $(100-200 \mu \mathrm{m})$ & $0-5$ & $0-5$ \\
Zeolites & $5-40$ & $15-25$ \\
Ichthyoliths & $70-100$ & $85-97$ \\
Volcanic glass & $0-3$ & None \\
Radiolarians & tr & $0-5$ \\
Foraminifer molds & tr & $0-1$ \\
\hline
\end{tabular}

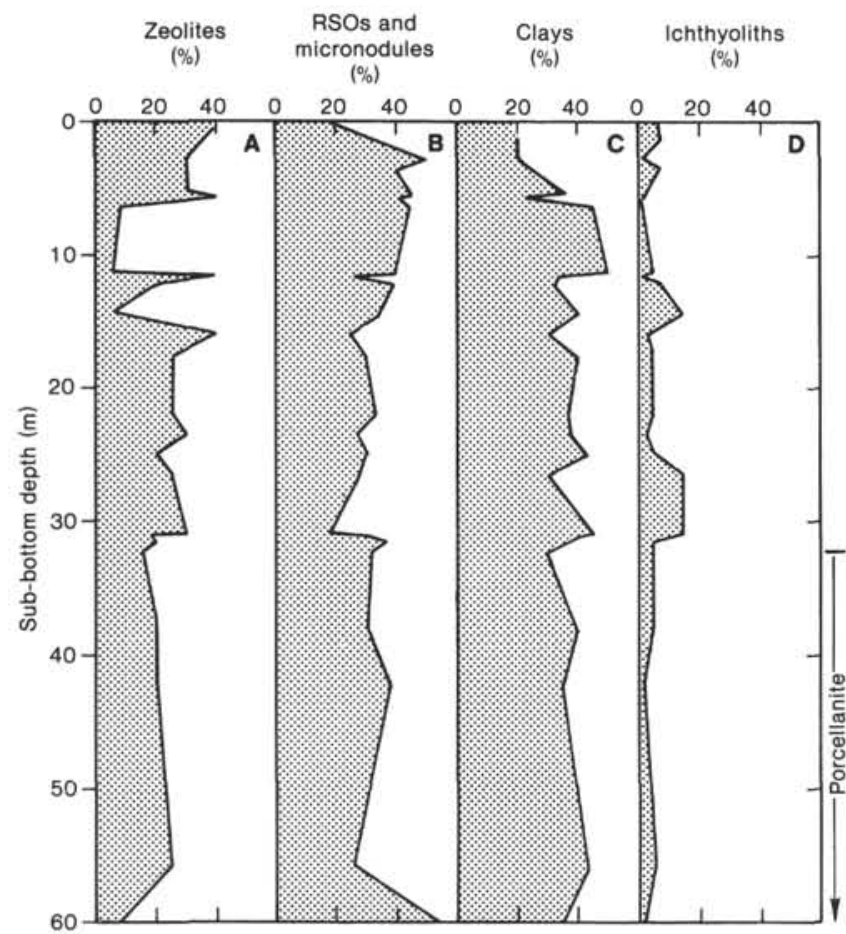

Figure 3. Estimates from smear slides of sediment components plotted versus sub-bottom depth for Hole 595A. A. zeolites. B. RSOs plus manganese micronodules. C. clays. D. ichthyoliths (fish denticles). The interval with porcellanites and cherts interbedded with clays is shown by the bracket to the right. Basalt/sediment contact was not recovered.

of zeolites and clays in the top $12 \mathrm{~m}$ of Hole $595 \mathrm{~A}$ and the high proportions of RSOs plus micronodules and ichthyoliths throughout. These are consistent with the extraordinarily low sedimentation rates inferred using the ichthyoliths (the Cretaceous/Tertiary boundary is at about $18 \mathrm{~m}$ in Hole 595A, according to Winfrey et al., this volume).

\section{Type "B": Porcellanite and Chert Interbedded with Pelagic Clay}

Type "B" sediments occur below the drill's first encounter with indurated radiolarian porcellanite at $31.4 \mathrm{~m}$ below the seafloor and extend to basement. The basalt/ sediment contact was not recovered. Throughout this interval, porcellanite occurs along with minor chert, interbedded with a soft, zeolitic pelagic clay. Because of the "hard/soft" nature of the sediment, pump pressures were high during rotary-style coring, hence recovery of the soft sediments was very poor. Typically, only a drilling breccia consisting of pelagic clay with platy or blocky pieces of porcellanite and chert was recovered.

The pelagic clay is dark reddish brown (5YR 2/2) to Core 9, where it darkens to black (5YR 2/1). The porcellanites are either a massive dark reddish brown (5YR $2 / 2$ ) or have subparallel color bands of dark reddish brown (5YR 2/2), yellowish brown (10YR 7/1), dark brown (7.5YR 4/4), and olive (10YR 4/4). Cherts are harder than porcellanites and dark gray (2.5YR 3/0).

Ranges in sediment components are indicated in Table 2 , and are fairly uniform among Type "B" sediments above Core 9 . There, zeolites decrease to $5 \%$, fish remains decrease to trace amounts, clays decrease to $34 \%$, and RSOs increase to $40 \%$, along with a pronounced increase in micronodules to $20 \%$. The latter probably accounts for the darker color of sediment in Core 9.

Radiolarians were extracted from both porcellanite and pelagic clay in Type " $B$ ' sediments. These include poorly preserved Early Cretaceous forms identified by A. Sanfilippo (reported in Winfrey et al., this volume). Internal molds of very small planktonic and benthic foraminifers also occur.

\section{RSOs and Zeolitic Sediment Components}

The acronym RSO, defined above, was adopted during Leg 34 to describe particles that have a size range from a few microns to tens of microns, are translucent to semiopaque, are usually isotropic, but are occasionally weakly birefringent, when observed in smear slides. Here, they have a variety of shapes, such as spherules, flakes, discs with raised rims, and aggregates. In other DSDP Initial Reports, they have been described as limonitic grains, amorphous Fe-Mn oxides, ferruginous aggregates, and micronodules. The term micronodule is used here for opaque particles that are 100-200 $\mu \mathrm{m}$ in diameter.

RSOs appear to be particularly abundant in sediments precipitated from hydrothermal exhalations near ridge crests and in slowly deposited reddish brown pelagic clays deposited well away from ridge crests in deep water below the calcite-compensation depth. Here, no calcareous materials of any kind were recovered, hence the entire sediment column has a high proportion of RSOs. For a more complete discussion of the origin of RSOs, see Quilty et al. (1973) and Bass (1973).

Precise identification of zeolites using the shipboard $\mathrm{X}$-ray diffraction unit was impossible because of the abundance of amorphous material, which produced much scattering. Tentative identification as phillipsite is based on crystal morphology. The most common crystal forms are clay- and silt-sized blades, sometimes twinned. Many larger crystals have pitted and irregular surfaces. 


\section{Coarse-Fraction Analysis}

One sample per core was boiled in Calgon for approximately $1 \mathrm{hr}$. each to disperse clay minerals. Residues were then washed through a 63-um sieve and the coarse fractions dried for examination.

The most abundant particles in the coarse fractions are fish remains, encrusted zeolites, and micronodules. In the lowermost type " $A$ " and most Type "B" sediments, radiolarians and internal molds of small foraminifers were also common.

The material encrusting the zeolites is possibly amorphous silica, generated by the diagenetic processes responsible for the porcellanite and chert. In X-ray analysis, only broad swells (no peaks) are produced by this material, which is, moreover, unreactive in hydrochloric acid. Its color varies from white to pale brown (the latter reflecting presence of RSOs). The zeolite encrustations vary from thin "meniscus"-shaped fillings between the arms of twinned crystals to coatings that completely engulf the crystals. Almost all radiolarians are heavily encrusted with similar material. It also forms silt- to coarse sand-sized spherules and pellets, which may be encrusted siliceous microfossils or internal molds of foraminifer chambers. In Section 1 of Core 1, near the mud line, such spherules and pellets make up almost $95 \%$ of the coarse fraction.

\section{Possible Interpillow Sediments}

One piece of brownish red, indurated, ferruginous sediment was recovered at the top of Core 595A-11. This is between two petrographically and chemically distinct basaltic rock types and therefore could be an interpillow sediment. No similar sediment was recovered in Core 9, just above basement, and dark brown radiolarian clay encrusts portions of several pieces of igneous rock near the top of Core 10, hence there is no indication that this type of sediment was deposited above the igneous rocks. However, igneous rocks similar to those in Core 10 were recovered at the top of Core 12 and presumably fell down the hole during retrieval of Core 11. Thus, there is no guarantee that the sediments at the top of Core 11 were cored in their proper relative stratigraphic sequence; they, too, could have fallen down the hole. Indeed, small sediment chips of similar lithology were brought up at the bottom of Core 12, and almost certainly these fell down the hole either from just above basement or the interval between recovered igneous rocks in Cores 10 and 11 .

An X-ray diffraction pattern of the sediment of Core 11 gave extremely high background, but lacked a basal smectite peak. It is thus not a claystone. Three somewhat irregular peaks occur at the region of highest background, but do not correspond to peaks for goethite or any other hydrous iron oxide. They are probably peaks representing mineral grains derived from the basalts. Of these minerals, plagioclase is probably responsible for the largest peaks at $21.5,27.3$, and $35.8^{\circ} 2 \theta$.

\section{Sedimentation at Site 595}

Important factors that must be considered in interpreting the sedimentary history of Site 595 are (1) the abundance of RSOs, Fe-Mn micronodules, and fish teeth throughout most of the section; (2) absence of carbonate sediments and poor preservation of radiolarians even where cherts and porcellanites were recovered; (3) a possible Jurassic age for basaltic basement, based on magnetic anomalies (H. W. Menard, personal communication, 1983); (4) an inferred high paleolatitude $\left(65+^{\circ}\right)$ at the time the basalts were extruded (Montgomery and Johnson, this volume); and (5) extremely slow accumulation rates for post-Cretaceous sediments based on ichthyolith biostratigraphy (Winfrey et al., this volume).

We tentatively interpret the Site 595 sedimentary history as follows. Basalts erupted at a high-latitude spreading ridge were initially capped with hydrothermal precipitates (cf. Boström and Peterson, 1966). No carbonate sediments were deposited at this time, either because of extremely low productivity or because this was prior to the late Cretaceous blooming of calcareous microfossils, probably both. Subsidence has carried this part of the Pacific plate below all subsequent calcite compensation depths; and the site has remained in an extremely low-productivity region of the Pacific ever since. Moreover, for most of the passage of the site to its present low latitude, it was remote from land sources of windblown material and volcanic ash, hence even rates of deposition of pelagic clay were minimal. Despite present proximity to the Tonga Trench, volcanic ash has not noticeably contributed to Neogene and younger sediments in the cores of Site 595.

Additional interpretation is provided in the Site 596 report.

\section{PORE-FLUID CHEMISTRY}

Pore fluids were squeezed from three samples in Cores $595 \mathrm{~A}-2,-3$, and -4 . Below this, low recovery and the presence of chert precluded obtaining samples of sufficient size that were also undisturbed and not contaminated by the seawater pumped down the hole to facilitate drilling. Data for $\mathrm{pH}$, alkalinity, salinity, chlorinity, and the abundances of calcium and magnesium are reported in Table 3. Only minor differences exist from sample to sample, and there are no significant trends with depth. Pore-fluid compositions are very similar to those of surface seawater and standard seawater, and most probably are identical to bottom water in the area. The compositions therefore do not reflect the occurrence of reactions between pore fluids and solids either in the sediments or in the basaltic rocks beneath the sediments.

\section{BIOSTRATIGRAPHY SUMMARY}

At Site 595, all three holes were rotary cored. Hole 595 consists of a $32-\mathrm{m}$ wash core with a small amount of pelagic clay recovered in the core catcher. Cores from Hole 595B consist of igneous rock. At Hole 595A, approximately $70 \mathrm{~m}$ of Cenozoic and Mesozoic sediments were cored continuously to basement with about $40 \%$ recovery. The upper $31 \mathrm{~m}$ (Core 1 to the top of Core 5) are zeolitic pelagic clay. The lower $39 \mathrm{~m}$ (Cores 5-9) are zeolitic pelagic clay interbedded with porcellanite and chert.

Microfossil groups are limited to rare foraminifers, radiolarians, and ichthyoliths. Radiolarians are poorly preserved but common in the lower chert-bearing pelag- 
Table 3. Summary of shipboard inorganic geochemical data.

\begin{tabular}{lccccccc}
\hline $\begin{array}{c}\text { Sample } \\
(\text { interval in cm) }\end{array}$ & $\begin{array}{c}\text { Sub-bottom } \\
\text { depth }(\mathrm{m})\end{array}$ & $\mathrm{pH}$ & $\begin{array}{c}\text { Alkalinity } \\
\mathrm{mEq} / \mathrm{L}\end{array}$ & $\begin{array}{c}\text { Salinity } \\
(\% \%)\end{array}$ & $\begin{array}{c}\text { Calcium } \\
(\mathrm{m} M)\end{array}$ & $\begin{array}{c}\text { Magnesium } \\
(\mathrm{m} M)\end{array}$ & $\begin{array}{c}\text { Chlorinity } \\
(\% \circ)\end{array}$ \\
\hline SSW & & 7.12 & 2.594 & 36.3 & 10.51 & 53.00 & 20.05 \\
IAPSO & & 7.82 & 2.710 & 37.4 & 10.55 & 64.54 & 19.375 \\
595A-2-7, 0-10 & $2.8-2.9$ & 7.01 & 2.942 & 35.2 & 10.45 & 49.73 & 19.54 \\
595A-3-2, 140-150 & $15.1-15.2$ & 7.09 & 2.520 & 33.8 & 10.53 & 50.11 & 18.83 \\
595A-4-2, 140-150 & $24.7-24.8$ & 7.16 & 2.618 & 34.1 & 10.45 & 49.73 & 19.54 \\
\hline
\end{tabular}

${ }^{\mathrm{a}} \mathrm{SSW}=$ surface seawater; IAPSO $=$ standard seawater.

ic clays. An abundant, but poorly preserved, assemblage with diverse forms is present at $61 \mathrm{~m}$ (Core 9, Section 1). Ichthyoliths are found throughout the hole, but are most common in the upper $15 \mathrm{~m}$ of Cenozoic sediments.

\section{Ichthyoliths}

Seventeen samples were taken at widely spaced intervals (average $1.5 \mathrm{~m}$ ) in the upper $26 \mathrm{~m}$ of Hole 595A (Table 4). Below $26 \mathrm{~m}$ (Cores 4-9), six samples were taken at 3- to 5-m intervals because of poor recovery. Ichthyoliths are present throughout the sequence, with peak abundances at $11 \mathrm{~m}$ (Core 2, Section 7), and to a lesser extent, at 14 and $15 \mathrm{~m}$ (Core 3, Sections 1 and 2). They are sparse to rare below $50 \mathrm{~m}$ (Cores 8 and 9).

Ichthyoliths suggest that the entire Cenozoic is contained in the upper 15 to $16 \mathrm{~m}$ (Cores 1-3) of Hole 595A (Table 3). Evidence of older forms mixed into younger assemblages is present throughout the sequence, probably as a result of drilling disturbance. Samples from Core 1 and the top of Core 2 are Miocene or younger, based on the first occurrences of Elliptical with line across, Short rectangular with striations, and Circular with line

Table 4. Age and depth of 23 samples from Hole 595A.

\begin{tabular}{clc}
\hline $\begin{array}{c}\text { Age } \\
\text { (based on } \\
\text { ichthyoliths) }\end{array}$ & $\begin{array}{l}\text { Core-Section } \\
\text { (interval in cm) }\end{array}$ & $\begin{array}{c}\text { Depth } \\
\text { to top of } \\
\text { sample (m) }\end{array}$ \\
\hline $\begin{array}{c}\text { Miocene or } \\
\text { younger }\end{array}$ & $1-1,11-15$ & 0.11 \\
& $1-2,11-15$ & 1.61 \\
Eocene- & $2-1,60-64$ & 3.40 \\
Oligocene & $2-2,60-64$ & 4.90 \\
& $2-5,60-64$ & 6.40 \\
& $2-7,0-4$ & 9.02 \\
& $3-1,50-55$ & 11.80 \\
& $3-1,55-57$ & 12.70 \\
& $3-2,50-55$ & 12.75 \\
Paleocene & $3-3,50-52$ & 14.20 \\
& $3-3,55-57$ & 15.75 \\
& & \\
Cretaceous & $4-1,60-64$ & 22.40 \\
or older & $4-2,60-64$ & 23.90 \\
& $4-2,64-66$ & 23.94 \\
& $4-3,24-29$ & 25.04 \\
& $4-4,24-29$ & 26.54 \\
& $4-6,22-27$ & 29.52 \\
& $5-1,82-85$ & 32.22 \\
& $5-7,30-37$ & 37.60 \\
& $8-3,130-136$ & 54.90 \\
& $8, C C(68-73)$ & 57.48 \\
& $9-1,77-82$ & 60.97 \\
\hline
\end{tabular}

across. The absence of Long ellipse and Narrow triangle ragged base and the presence of single specimen of Long triangle stepped margin in Core 1 samples suggest that Pliocene and Quarternary sediments are either absent or exceedingly thin. The presence of Elliptical with line across in a sample from Core 2, Section 1 suggests that the sample is not older than middle Miocene.

Sections 2 to 5 of Core 2 are Eocene-Oligocene. An irregular and conflicting pattern of first and last occurrences in this part of Hole 595A makes a distinction between Oligocene and Eocene unreliable. However, the sample from Core 2, Section 2 appears to be Oligocene based on the first occurrences of Large with numerous lines, Small dentritic few radiating lines, and Rounded apex triangle, as well as the fact that it is below Miocene events including the first occurrences of Small triangle long striations, Elliptical with line across, Circular with line across, and Short rectangular with striations.

Core 3, Section 2 is Paleocene, based on the first occurrences of Triangle medium wing, Triangle with triangular projection, and Triangle radiating inline. The $\mathrm{Pa}-$ leocene/Eocene boundary is between Core 2, Section 5 and Core 3, Section 2. The presence of Beveled triangle mid inline, Short triangle bowed inline, and Flexed triangle asymmetric in samples from Core 3, Section 1, suggests that this boundary most probably occurs between Cores 2 and 3. The presence of Cretaceous subtypes (Centrally striated triangle and Wide triangle projection) in the assemblage from Core 3, Section 2 suggests disturbance and/or reworking.

Cores 4 to 9 are Mesozoic (Table 4), based on the presence of Wide triangle projection, Blunt triangle dendritic inline, Triangle long inline, Triangle square inline, and the first occurrences of Capped triangle and Small triangle keeled edges. The Cretaceous/Tertiary boundary is between Core 3, Section 2 and Core 4, Section 1. A mixture of Cretaceous and Cenozoic forms in samples from Section 3 of Core 3 does not allow a more precise placement of the boundary. Mesozoic ichthyoliths have not been studied sufficiently to determine age divisions.

\section{IGNEOUS ROCKS}

\section{General Appearance and Composition}

Drilling at Site 595, we encountered three distinct types of basaltic rock (Units 1, 2, and 3 in Figure 4). Unit 1, the uppermost, consists of gray to brownish, fine- to medium-grained, slightly vesicular aphyric basalt. The color is distinctly lighter (in fresher specimens) than in typ- 


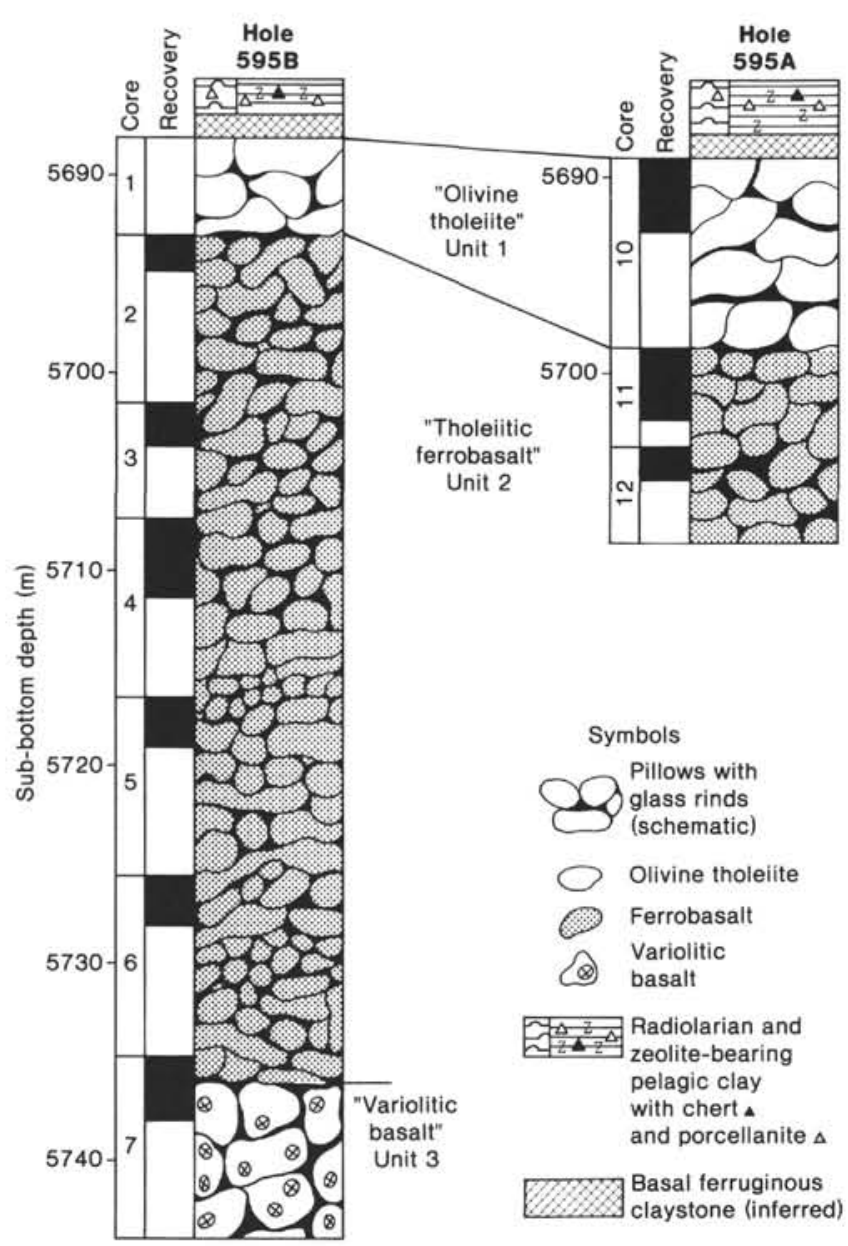

Figure 4. Basement lithology, Holes 595A and 595B.

ical abyssal tholeiites or ferrobasalts, and the rock appears to be quite felsic in composition. Compositionally, however, the basalt is the least fractionated of the three types cored (Saunders, this volume), having the highest $\mathrm{MgO}, \mathrm{Cr}$, and $\mathrm{Ni}$ contents.

Basalt Unit 2 lies below Unit 1 and consists of dark gray, fine-grained aphyric basalt with the petrographic and compositional attributes of abyssal ferrobasalt (see below and Saunders, this volume). It is the most fractionated of the three basalt types.

Unit 3 basalts are dark gray, aphyric, fine-grained, and variolitic. They are characterized by purplish brown to dark gray mottling on cut surfaces, which is apparently related to a combination of formation of variolites and of incomplete magma mixing (see petrographic descriptions, below). This rock type is intermediate in composition between the two basalt types above it, but overall has the composition of a fractionated abyssal tholeiite (Saunders, this volume).

All of the basalts are highly fractured and veined, with Unit 2 basalts showing the most fracturing and Unit 1 , the least. Fractures are irregular and anastomosing, breaking the rock into polygonal blocks. Within Unit 2, fracture spacing is a few centimeters. All of the rock shows alteration banding, distinguished as being either lighter or darker, but mainly darker, than adjacent rock.
The bands parallel fractures and veins and vary from a few millimeters to over $2 \mathrm{~cm}$ wide. Multiple, overlapping bands of alteration are common. Veins in Unit 1 are filled with iron hydroxides and carbonate minerals, those in Units 2 and 3 are filled with iron hydroxides, green smectites, and carbonates.

Igneous Units 1 and 2 were sampled in both Holes 595A and 595B, whereas Unit 3 was encountered in Hole 595B only (Fig. 4). Unit 1 was sampled between 69.8 to $79.4 \mathrm{~m}$ below seafloor in Hole 595A, with $3.8 \mathrm{~m}$ of rock recovered from the $9.6 \mathrm{~m}$ drilled. Only two small Unit 1 cobbles were recovered in Hole 595B, one from the core catcher of the first core to reach basement (Core 595B1), the other the topmost piece of the second core (Core 595B-2). Neither the upper nor the lower unit boundaries were sampled, hence Unit 1 may be either fairly constant in thickness between the two holes $(3.6 \mathrm{~m})$, or, more likely, it may thin from 9 to less than $3 \mathrm{~m}$ between Holes $595 \mathrm{~A}$ and 595B.

Drilling at Hole 595A bottomed in Unit 2, at $18.6 \mathrm{~m}$ below the sediments, with $5.4 \mathrm{~m}$ of Unit 2 rock recovered. A chilled margin occurs on the topmost piece of Unit 2 basalt recovered, and a piece of indurated ferruginous sediment of possible hydrothermal origin is immediately above this, representing material deposited between eruptions of the two basalt types. In Hole 595B, $13.6 \mathrm{~m}$ of Unit 2 basalts were recovered in $42.2 \mathrm{~m}$ drilled, with the lowest rocks sampled at a depth of $45.2 \mathrm{~m}$ below the sediments.

Igneous Unit 3 was cored below this, between $\mathbf{4 5 . 2}$ and $53.8 \mathrm{~m}$ below the sediments in Hole 595B, with $2.7 \mathrm{~m}$ recovery. The thickness of this unit below that point is unknown.

All of the basaltic units consist of multiple flows or pillows. Within Units 2 and 3, glassy margins and grainsize differences clearly distinguish the lavas as pillows with an average estimated diameter of $50 \mathrm{~cm}$. Some of the glass margins are inclined or vertical, confirming that these are not horizontal flows.

Unit 1 lacks glass margins, but several instances of grain-size fining toward core-piece edges indicate that at least three internal flows are present, having an average 1.3-m thickness. These may be either pillows or horizontal flows.

\section{Petrography}

Unit 1 basalts are fine to medium-grained, and have crystals with spherulitic to skeletal morphologies. The rocks consist principally of plagioclase, clinopyroxene, and titanomagnetite, plus clay-mineral and iron oxyhydroxide alteration products. Rare, scattered, completely transformed olivine pseudomorphs occur in the finestgrained samples, along with scattered, tabular plagioclase microphenocrysts.

Most samples are fairly coarse grained. In them, plagioclase comprises $35-40 \%$ of the rock an occurs as subhedral laths averaging $0.5 \mathrm{~mm}$ in length. Clinopyroxene lies intersertal to plagioclase with anhedral to subhedral shape. Crystals average less than $0.3 \mathrm{~mm}$ diameter and make up $25-30 \%$ of the rock. Pyroxene and plagioclase are commonly intergrown, indicating coeval crystalliza- 
tion. Minimum measurements of $2 \mathrm{~V}+$ of the pyroxenes are fairly low (35-40\%), indicating compositions of subcalcic augite, but not pigeonite. In reflected light, titanomagnetites are seen to have skeletal morphologies where they are not replaced by secondary iron oxyhydroxides. There are some large, reflective opaque minerals that have the outline of phenocrysts, but that are pure secondary iron oxide (hematite?), as determined by electron microprobe (J. Natland, unpublished data). These may originally have been either titanomagnetite or $\mathrm{Cr}$ spinel phenocrysts. The latter is suggested by their proximity to altered olivines in one sample. An original shipboard interpretation was that these were titanomagnetite phenocrysts, indicating a quite evolved composition for the rocks. This and the light color of fresh hand specimens suggested to one shipboard scientist (who now chooses to remain as anonymous as possible) that Unit 1 might have the composition of abyssal andesite, comparable to some lavas of the Galapagos Spreading Center (Perfit and Fornari, 1983). This is, of course, disproven by the compositions of the lavas (Saunders, this volume) and by failure of microprobe study to verify that the large opaques are titanomagnetite phenocrysts.

Amorphous brownish and grayish clay minerals occupy up to $40 \%$ of the ground mass of Unit 1 rocks, replacing interstitial glass and portions of silicate minerals along grain boundaries. Titanomagnetites are largely replaced by a secondary phase that is darker gray in reflected light. Their alteration corresponds to the lower temperature oxidation Stage 5 of Johnson and Hall (1978) - almost complete replacement of the opaque grains by opaque material.

Unit 1 basalts have about $1 \%$ vesicles, circular in cross section, $1 \mathrm{~mm}$ or less in diameter, and commonly filled or lined with secondary minerals, especially in the alteration bands.

Rocks of Unit 2 range from glassy to microlitic. The microlitic rocks have $20-40 \%$ plagioclase, $15-25 \%$ intersertal clinopyroxene, $5-15 \%$ interstitial titanomagnetite, and $14-45 \%$ interstitial glass, the latter now altered to optically amorphous clay minerals. Grain size varies from fine-grained to glassy, plagioclase ranging from 0.5$0.8 \mathrm{~mm}$ in length. Clinopyroxene crystals are poorly developed, having mainly the morphologies of spherulites even in the coarsest-grained rocks. They are largely replaced by clay minerals. Titanomagnetite occurs as fine, angular, interstitial grains and is usually as altered as the titanomagnetite in Unit 1 basalts. Crystals in most of the rocks are skeletal, but the rocks also have extensively developed pilotaxitic texture, in which plagioclase laths show preferred dimensional orientation. A third, minor, texture is one wherein a small percentage of plagioclase laths having dendritic extensions at the tips of the grains lie within a matrix of ragged sheaves of probable clinopyroxene plus plagioclase fibers, interstitial titanomagnetite, and altered glass.

Unit 2 basalts have a few scattered euhedral plagioclase laths between $0.5-1.0 \mathrm{~mm}$ in length. Several are slightly rounded, suggesting that minor resorption has occurred. Two clinopyroxene phenocrysts were found in the several thin sections examined. Both are subhedral and about $0.3 \mathrm{~mm}$ in diameter. In glassy and fine-grained spherulitic portions of the rocks, tiny euhedral crystals of plagioclase may be intergrown with even smaller clinopyroxene crystals, but such intergrowths are much less abundant than isolated plagioclase phenocrysts.

Petrographic evidences that these are ferrobasalts are (1) absence of olivine; (2) occurrence of rare plagioclase and clinopyroxene microphenocrysts, plus, even more rarely, occurrence of the two intergrown in crystal aggregates; (3) abundance of titanomagnetite in the coarsergrained rocks; (4) occurrence of extremely dark, almost completely opaque zones of coalesced spherulites within about $1 \mathrm{~cm}$ of glassy margins; and (5) occurrence of very dark brown isolated plagioclase spherulites set in the glassy margins (cf. Natland, 1980).

Unit 2 basalts have only extremely rare, tiny, vesicles, invariably filled with orange or green clays.

Unit 3 basalts contain sparse plagioclase and very rare olivine microphenocrysts, the latter completely replaced by secondary minerals. The most striking feature of the rocks is their mottled appearance, manifested in thin sections by patches of completely contrasting grain size, crystallinity, and crystal morphologies. Patches are either light colored, and have abundant skeletal, extremely acicular plagioclase crystals, or are darker brown, with only a very few skeletal plagioclases, but consisting of diffuse sheafs or bundles of tiny needles of plagioclase and probably clinopyroxene. The brown color reflects the greater susceptibility of these zones to oxidative alteration.

The origin of the patches is uncertain. On the one hand, a number of the smaller, coarser-grained patches appear to consist entirely of unusually coarse-grained single-sheaf spherulites. On the other hand, coalesced patches of these coarser-grained patches have extremely irregular boundaries, with individual acicular, elongate plagioclase microlites straddling the boundaries. The patches are only obvious at particular distances from cooling-unit boundaries (between 5 and $15 \mathrm{~cm}$ ). The zones of spherulites nearest glassy rims are, to all appearances, quite homogeneous. Isolated spherulites and round, coalesced spherulites are similar in size, shape, and color. It is only toward the interior of the rock about $3-5 \mathrm{~cm}$ from glassy margins, where some differentiation into coarser and finer grained spherulitic zones occurs. This differentiation is most pronounced for only about another $10 \mathrm{~cm}$ or so toward cooling-unit interiors. In the coarsest-grained rocks, it is barely discernible, mainly as areas of thin sections in which clinopyroxene crystals are somewhat larger and more abundant than elsewhere.

We tentatively interpret this phenomenon to reflect either slight compositional or thermal contrasts between adjacent patches of lava suddenly radically supercooled by eruption onto the seafloor. Both compositional and thermal contrasts could be produced by incomplete magma mixing. The possible thermal contrasts could reflect contrasting degrees of superheating or supercooling the melts would have, for example, after incomplete mixing. This in turn would influence the abundance of centers of nucleation for crystals (Walker et al., 1979). Additional compositional factors might be (1) contrasts in 
melt composition; (2) heterogeneous volatile distribution; or (3) different oxygen fugacities, any of which could readily be produced by magma mixing, but which might also be produced by non-uniform access of seawater to magma-chamber and conduit systems.

\section{Fractures and Veins}

It is possible to determine the sequence of vein-mineral formation by the relationships of fractures to one another. Moreover, there is a clear relationship between alteration banding and certain fractures. Briefly, Unit 1 basalts contain fractures lined with iron oxyhydroxides. The centers of these fractures in turn are occupied by carbonate minerals (both aragonite and calcite, identified by X-ray diffraction procedures). However, branching from these are additional fractures lined with carbonate minerals alone. Inspection of thin sections reveals that the alteration banding itself is controlled in the rock by many tiny fractures along which narrow veinlets of iron oxyhydroxides occur. The pervasive staining of the rock results from fractures occurring at the tiniest scale of all, crossing individual mineral grains. Faint films of iron oxyhydroxides can be seen to cross-cut individual plagioclase grains along such tiny fractures. It is obvious, then, that the stained zones result from formation of fractures on all scales within the rock, and penetration into the rock of fluids bearing the same iron oxyhydroxide materials that occur in the largest veins.

Unit 2 and some Unit 3 basalts contain myriad fractures lined with (1) iron oxyhydroxides, (2) green clays, (3) iron oxyhydroxides again, and (4) carbonates, formed in that order. Each episode of vein-mineral formation was accompanied by formation of new fractures lined exclusively with the particular vein mineral then being deposited. Thus, all vein minerals formed and alteration processes probably occurred at or near the spreading ridge from which these basalts erupted. Vein mineralization episodes 1 and 2 occurred following after eruption of Unit 2 basalts (affecting only Units 2 and 3) and episodes 3 and 4 after eruption of Unit 1 basalts (affecting all 3 units), accounting for the cross-cutting relationships and distribution of vein minerals. The iron oxyhydroxides are analogous to the materials that produce the basal ferromanganese sediments of many DSDP sites on younger crust in the eastern Pacific and the amorphous iron-oxyhydroxide hydrothermal precipitates of the East Pacific Rise (Boström and Peterson, 1966). The green clays are analogous to nontronites produced by hydrothermal activity at such places as the Galapagos hydrothermal mounds (e.g., Corliss et al., 1978; Hekinian et al., 1980). The Site 595 basalts offer one of the clearest indications of the effects of typical hydrothermal activity at a rapidly spreading ridge acting within the basalts. Such processes have heretofore not been obvious in poorly recovered basalts drilled in younger crust nearer the East Pacific Rise.

\section{Relationship to Magmatic Processes at Spreading Ridges}

All the basalts are typical depleted abyssal tholeiites (Saunders, this volume). Two of the three units (2 and 3) are quite fractionated; lavas such as these are found primarily on rapidly spreading, but rarely on slowly spreading, ridges. All of the basalts are substantially aphyric, lacking even a few of the large phenocrysts so typical of basalts of the Mid-Atlantic Ridge. In this respect, they are again reminiscent of basalts of the East Pacific Rise (e.g., Natland, 1980; Perfit and Fornari, 1983). The three rock types cored at Site 595 apparently represent a considerable range in the degree of fractionation, although not even the Unit 1 basalts are so little fractionated as to approach a potential parental magma composition. Indeed, Saunders (this volume) argues that the three basalt types cannot be related in every respect quantitatively by closed-system fractional crystallization. Instead, each lava type retains to some degree the imprint of its original parental precursor, but modified in all likelihood by both fractional crystallization and mixing in a shallow crustal environment. Site 595 represents one of the few places in the Pacific where even so many as three lava types are available in a single drill hole to evaluate magma-chamber processes. The lava compositions provide no indication that magmatic processes acting at a Mesozoic rapidly spreading ridge were much different than they are now, but they provide a tantalizing hint of the complexity of processes which we have not yet been able to evaluate in younger crust of the East Pacific Rise.

\section{PHYSICAL PROPERTIES}

\section{Physical Properties Methods}

The following physical properties measurements were made on the cores on board Glomar Challenger: sonic velocity, vane shear strength, thermal conductivity, and bulk density by a variety of methods. These methods included running whole core sections through the Gamma-Ray Attenuation Porosity Evaluator (GRAPE) as well as the use of small cylindrical samples which were irradiated by the GRAPE for 2 min. each before being used for direct water-content determinations. No further measurements have made ashore. Although downhole logging was planned for Leg 91, a decision was made to remove the logging equipment shortly beforehand and the borehole instrumentation package (BIP) was the only quantitative downhole tool deployed during the leg.

\section{Sonic Velocity}

Sonic-velocity measurements were made at $400 \mathrm{kHz}$ using the Hamilton frame apparatus described by Boyce (1973). With this equipment, samples are gently pressed between a pair of transducers. The separation of the transducers and the additional traveltime of a pulsed waveform though the sample resulting from inserting it between the transducers are used to calculate compressional-wave velocity.

Measurements were made at least $4 \mathrm{hr}$. after core recovery to allow thermal equilibration to occur. Normally sound was transmitted normal to the core axis. Frequently wetting of the transducer faces with glycerine was necessary to obtain good acoustic contact. Sediment measurements were obtained on split cores in a polycarbonate liner. Care was taken to minimize drying out of 
these cores before taking observations. Obviously disturbed sediment was avoided but since the brown clay was naturally homogeneous in appearance, apparently suitable samples may not always have been undisturbed. Basalt measurements were usually made through cylindrical cores removed from the liner but sometimes parallel-sided slabs were used. Samples representative of massive, veined, and cracked rock types were chosen as soon as the liners were split. They were then stored in seawater until thermally equilibrated.

The apparatus was calibrated at the start of the leg. The only timing error lay in the interval frequency source within the oscilloscope. This source was checked with a digital frequency meter. The dial micrometer was harder to calibrate because of the lack of a good quality micrometer. Eventually a plastic micrometer was used since it gave results closest to the expected velocities of the aluminum and plastic DSDP standards. A calibration factor of 1.0028 was used in calculating sonic velocity to allow for the time and distance errors in the equipment. The sum of all the observational errors is $\pm 0.025 \mathrm{~km} / \mathrm{s}$ in both sediment and basalt velocities. Further sources of error resulting from variable liner properties and highly disturbed sediment around the core exterior have been discussed by Bennett and Keller (1973). During Leg 91, one of the two operators made most of the measurements, so that between operators, inconsistencies were minimal.

\section{Shear Strength}

The undrained shear strength of the sediment cores was measured using a modified Wykeham Farrance Model WF 2350 vane-shear apparatus as described by Boyce (1977). With this device, torque and rotational strain are measured independently as a paddle or vane, immersed in the sediment, is steadily rotated until the sediment fails about a cylindrical surface.

On Leg 91 the vane was always inserted vertically normal to the core axis into the cut surface of split cores. For the weak sediments of Leg 91, the largest $12.72 \times$ $25.4 \mathrm{~mm}$ vane (Vane 4) and the weakest spring (Spring 1) were usually used. Obviously disturbed sediment was avoided but since the brown clay was naturally homogeneous apparently suitable samples may not always have been undisturbed. No measurements were made on especially remolded samples. The uncertainty in calculated shear-strength resulting from observational errors is about $2 \%$.

Although undrained shear strength is an important soil mechanics parameter, it is very susceptible to disturbance of the sample. Demars and Nacci (1978) were skeptical of how representative shipboard shear-strength measurements could be of in situ conditions because of likelihood of remolding occurring during coring. It is not clear that these comments apply to samples obtained with the hydraulic piston core (HPC) however; the HPC was used extensively at Site 596 but not at Site 595 . Comparisons of the shear strength of piston (HPC) and normal rotary cores suggest that the piston cores provide more consistent, less scattered data (Shephard et al., 1982) but that essentially the same downhole trends are observed whichever type of coring is used (Einsele, 1982). In view of the radical difference between the two coring techniques, this suggests that any systematic differences between in situ and shipboard shear strengths are because of factors other than coring disturbance, such as change of stress field (Einsele, 1982) and swelling (Demars and Nacci, 1978). No attempt has been made to correct our measurements to in situ values.

\section{Gamma-Ray Attentuation Porosity Evaluator (GRAPE)}

The GRAPE provides a rapid continuous method of obtaining porosity and bulk density estimates of rock cores. The principles, a description of the equipment, and methods of interpretation are given by Evans and Cotterell (1970) and by Boyce (1973, 1976). However, the method does have severe limitations in providing estimates of bulk density (see also Bennett and Keller, 1973).

1. The Compton mass attenuation coefficients $(\mu)$ for seawater and quartz, which must be used in the computation of bulk density, are dependent on equipment settings and should be verified directly using seawater and quartz standards (Boyce, 1976).

2. In some lithologies the use of the $\mu$ value for quartz is not appropriate and the presence of significant amounts of montmorillonite, chlorite, pyrite, and other less common minerals leads to errors of several percent (Evans and Cotterell, 1970; Boyce, 1976).

3 . In the continuous mode, gamma-ray intensity is averaged over $2 \mathrm{~s}$. The random emissions of the gammaray source are such that errors of up to $\pm 11 \%$ can arise from the use of such a short counting interval (Boyce, 1976). Use of the equipment in the static mode, where intensity is averaged over $2 \mathrm{~min}$., provides a precision of \pm 1 or $2 \%$, but clearly this cannot be done routinely on all cores.

4. Swelling of the cores, in which additional water is entrained (Demars and Nacci, 1978), and cracks and fractures obviously will lead to low calculated densities.

5. Variations in core diameter are an important source of random error, since calculated density is inversely dependent on the width of sample traversed by the gamma-ray beam. If undersized cores, more common in hard rocks when the bit bearings have loosened, but which also can result from overpumping, are not allowed for systematically, then low calculated densities result. For example, cores undersize by 4,8 , and $12 \mathrm{~mm}$ in diameter give density errors of 6,13 and $21 \%$, respectively.

6 . Variations of liner thickness have also been reported (Bennett and Keller, 1973) and will contribute to errors in calculated density.

If porosity is estimated from the GRAPE bulk density then the above sources of error are compounded by uncertainties in the correct grain density to use for different lithologies. The method of obtaining 1-in. diameter cylindrical subsamples of the cores for 2-min. GRAPE measurement is described by Prell, Gardner, et at. (1982). The same samples were subsequently weighted, dried at $110^{\circ} \mathrm{C}$, and reweighed on board to obtain water content, porosity, and bulk density by the ASTM standard technique for water-content measurements (ASTM, 1967, 
Prell, Gardner, et al., 1982). Further discussion of the derivations from these gravimetric measurements of water content, saturated bulk density, porosity, and grain density can be found in Prell, Gardner, et al. (1982).

\section{Thermal Conductivity}

Thermal-conductivity measurements were made on one or two selected sections from each core. Initially, these measurements were intended to complement downhole temperature measurements to enable heat flow to be calculated. However, lack of time excluded the temperature measurements and here the thermal conductivity measurements alone are reported. The selected sections were kept unopened in the laboratory for several hours to ensure they were nearly equilibrated to ambient temperature. Thermal-conductivity measurements were then made by the standard needle-probe technique (Von Herzen and Maxwell, 1959). Needles were inserted in small holes drilled in the unopened liner.

\section{Physical Properties Results}

Physical property measurements made on cores Holes 595A and 595B include shear strength, sound velocity, continuous GRAPE, 2-min. GRAPE counts on individual samples, water content using the cylinder technique, and thermal conductivity.

\section{Shear Strength}

The Wykeham Farrance vane-shear apparatus in the motorized mode was used to measure shear strengths of split cores of pelagic clay. It was found empirically that, in view of the weakness of these sediments, the weakest spring and largest vane should be used. Observations from the top $31 \mathrm{~m}$ of the hole are given in Figure 5. All but three of the values lie in the range $2.5-6.9 \mathrm{kPa}$. These three values (15.4-18.4 kPa) are representative of the firmest parts of cores from the top $2 \mathrm{~m}$. Although the data show reasonable internal consistency, it was difficult to assess the degree, or even the presence, of mechanical disturbance to the cores by the coring process because of their very uniform appearance. Refer to the Sediment Lithology section for a discussion of disturbance.

\section{Compressional-Wave Velocity}

Compressional-wave velocities were measured on samples of pelagic clay, chert, and basalt at Site 595 (Fig. 6). Very little variation was seen in the velocity through the clays (range 1.46-1.54 km/s). Surprisingly, the highest values were obtained in the top $2 \mathrm{~m}$ of the hole. The only sample of chert large enough to be worked on gave velocities of $3.73-3.89 \mathrm{~km} / \mathrm{s}$. The basalts exhibited quite a wide range of values $(4.15-5.24 \mathrm{~km} / \mathrm{s})$. The mean of 59 measurements was $4.72 \mathrm{~km} / \mathrm{s}$, with over $85 \%$ of the observations falling in the range 4.4-5.0 km/s (Fig. 7). Preliminary analysis suggests that the presence of brown and green veins is associated with relatively low velocities $(4.15-4.52 \mathrm{~km} / \mathrm{s})$. The most massive (uncracked and unveined) samples yield relatively high velocities (4.71$5.24 \mathrm{~km} / \mathrm{s}$ ).

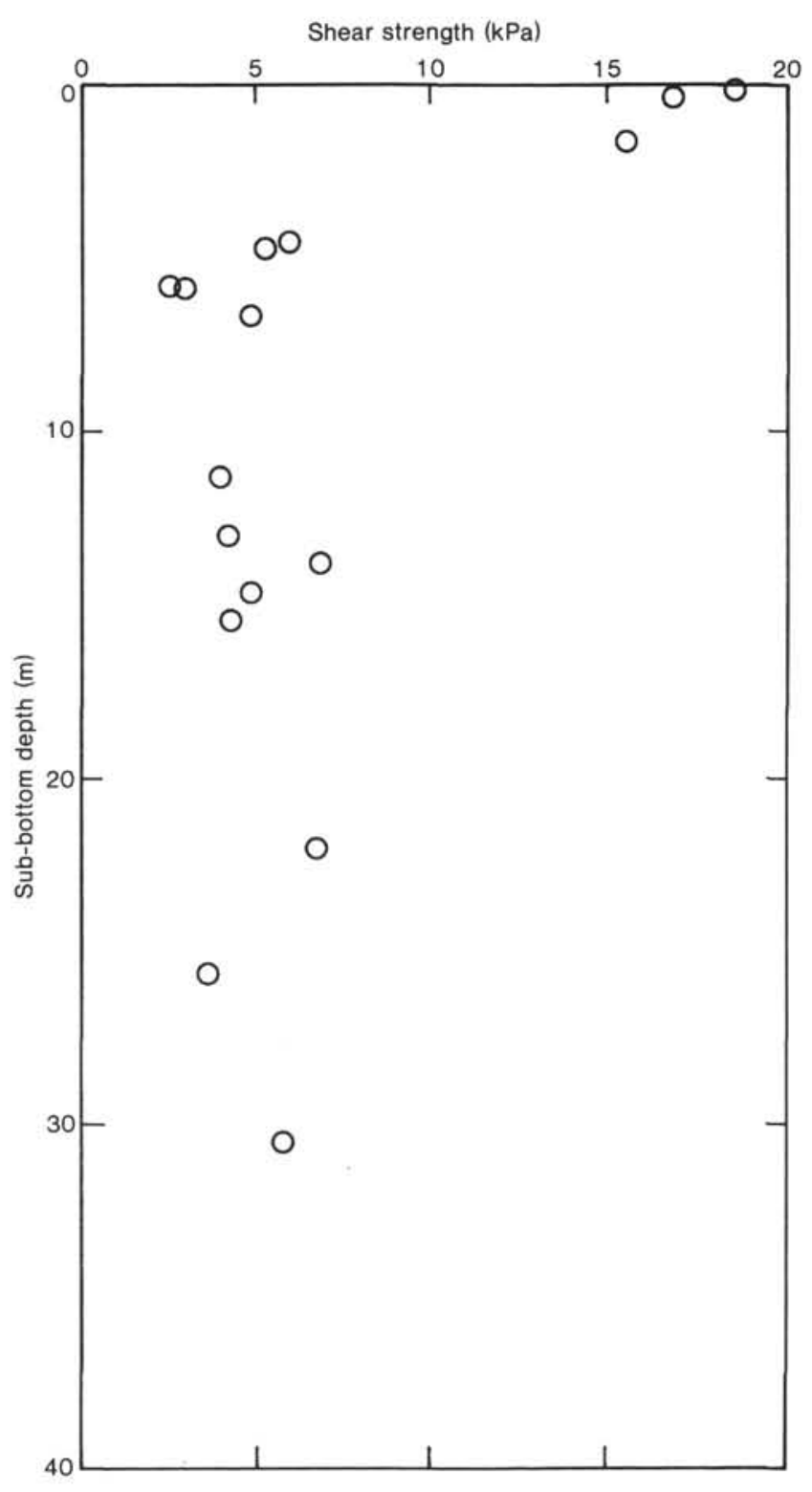

Figure 5. Shear strength versus sub-bottom depth for sediments cored in Hole 595A.

\section{Density}

Soft sediments were run continuously through the GRAPE while still in the uncut core liners. Discrete samples of these sediments were then collected after splitting, using the cylinder technique described by Boyce (1976). Wet-bulk densities of these samples were determined from 2-min. GRAPE counts and from measurements made as part of the water-content determinations. When basement rock was reached, 2-min. GRAPE counts were run on individual rock fragments, usually cylindrical cores.

Figure 8 includes a plot of wet-bulk density of the soft sediment cored versus depth below seafloor. Results from both GRAPE and water-content determinations are shown. The results from the water-content measurements appear to have less scatter than those from the GRAPE. 


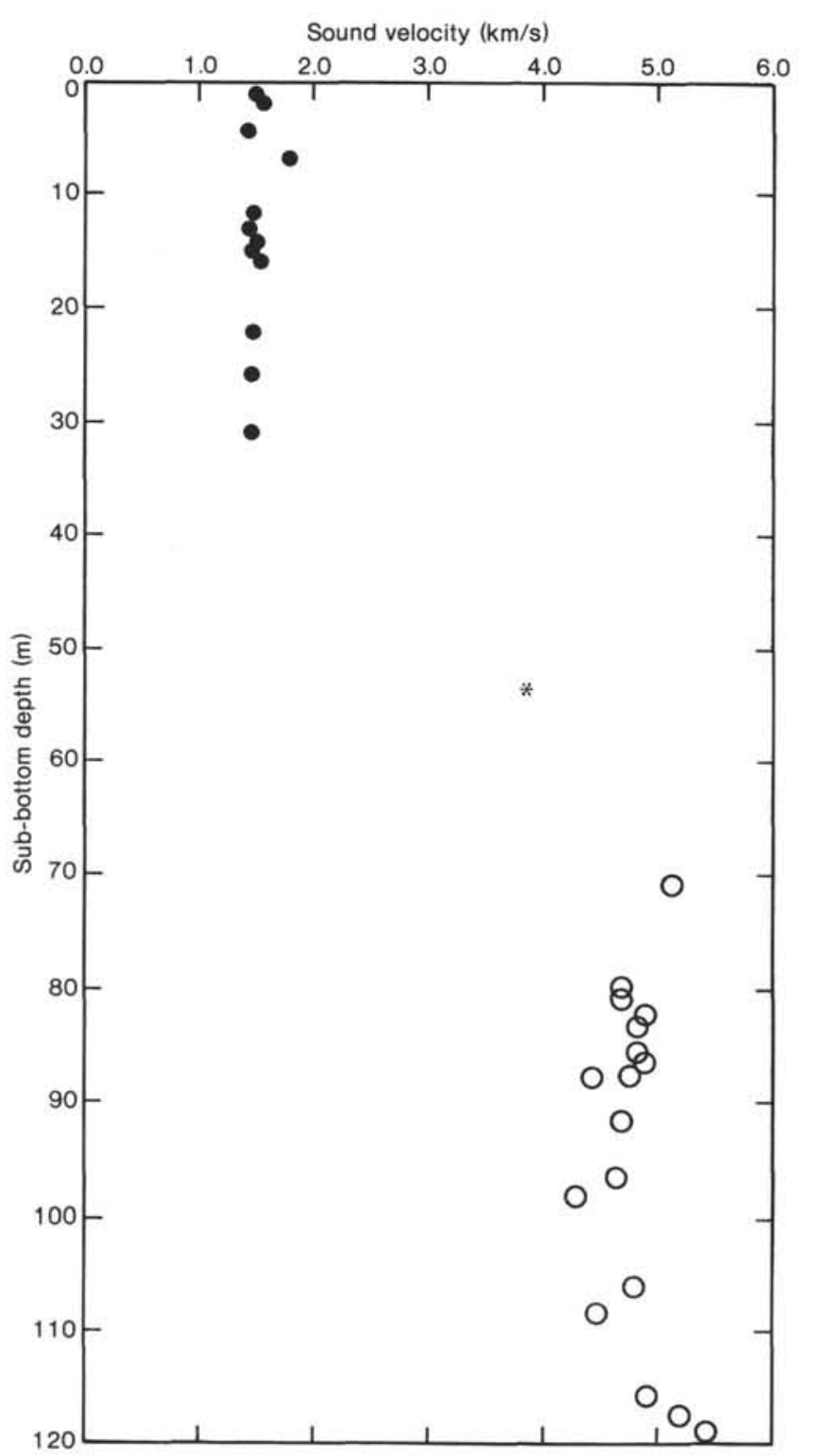

Figure 6. Sound velocity versus sub-bottom depth for sediments and basalts cored in Holes 595A and 595B. = soft sediments; * = cherts; $O=$ basalts.

All but one of the values lies between 1.22 and $1.30 \mathrm{~g} /$ $\mathrm{cm}^{3}$. Difference in values obtained from the two methods are never greater than $6 \%$. Other results from the water-content data are shown in Table 5.

The wet-bulk density of the basalts plotted against depth downhole is also shown in Figure 9. Included on this graph is a single sample of chert (at $\sim 55 \mathrm{~m}$ subbottom), which has an average density of $2.46 \mathrm{~g} / \mathrm{cm}^{3}$. The density of the basalts remains fairly constant with increasing depth, and falls in the range of 2.51 to $2.74 \mathrm{~g} / \mathrm{cm}^{3}$.

\section{CORRELATION OF PHYSICAL PROPERTIES AND UNDERWAY GEOPHYSICS}

The three main lithologies found at Site 595 were zeolitic pelagic clay, cherts interbedded with clays, and basalts. Very little variation was seen in the sonic velocities

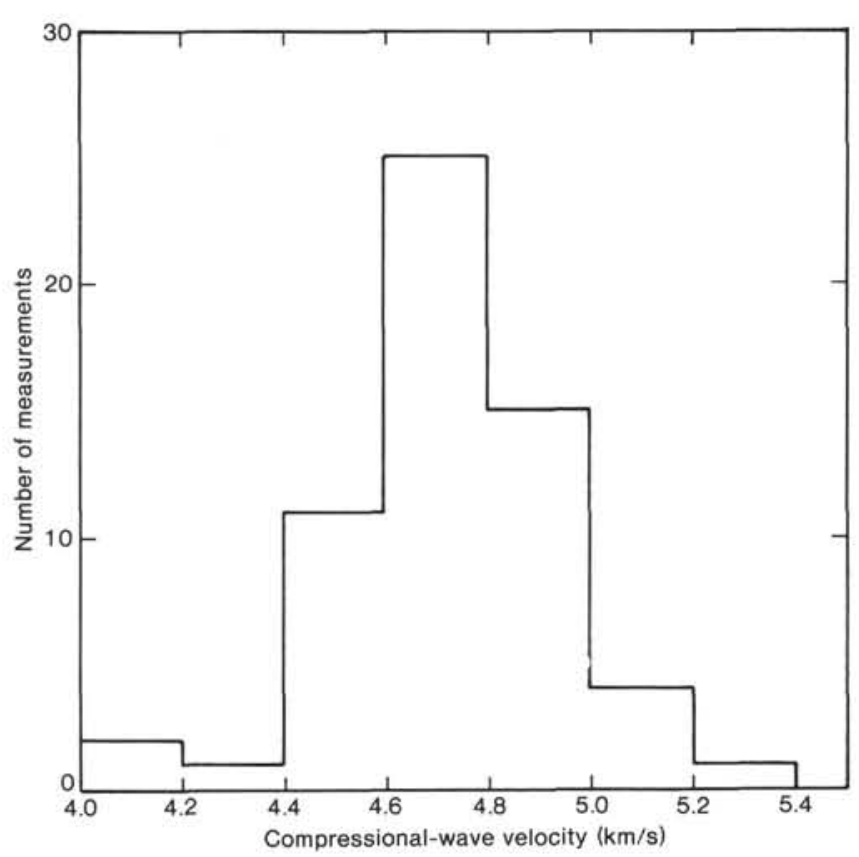

Figure 7. Histogram of compressional-wave velocities measured in 59 basalt samples recovered at Site 595 .

and densities of the pelagic clays. Average values were measured at $1.5 \mathrm{~km} / \mathrm{s}$ and $1.25 \mathrm{~g} / \mathrm{cm}^{2}$. The one chert sample measured gave values of $3.8 \mathrm{~km} / \mathrm{s}$ and $2.46 \mathrm{~g} /$ $\mathrm{cm}^{3}$. Measurements of basalt yielded average values of $4.72 \mathrm{~km} / \mathrm{s}$ and $2.65 \mathrm{~g} / \mathrm{cm}^{3}$.

During the site survey, water-gun and $3.5-\mathrm{kHz}$ records were obtained. The water-gun records may be compared with the composite lithology (Fig. 10). Arrows on the records indicate the approximate location of Site 595. The $3.5-\mathrm{kHz}$ depth sounding profile shows a strong reflection off the top of the chert layer. The time interval between the surface and chert reflector (assuming a velocity of $1.5 \mathrm{~km} / \mathrm{s}$ ) corresponds reasonably well to the thicknesses drilled in the hole. No coherent basalt reflection is seen. This is probably because of the rapid attenuation of the $3.5-\mathrm{kHz}$ source in the sediments. The strongest reflector seen on the single-channel water-gun reflection profile, however, is the top of the basalt. Reflections from the chert are not as strong or continuous as from the basalt reflector. Correlation of lithologic depth with two-way traveltime on the water-gun section is hindered by uncertainties in chert velocities.

\section{SUMMARY AND CONCLUSIONS}

The most important objective of Leg 91, emplacement of the DARPA/NORDA Marine Seismic System (MSS), was achieved at Site 595. The emplacement was not without problems or delays, but these were dealt with as they arose with patience, ingenuity, and resourcefulness. The operation required an unusual degree of teamwork and cooperation on the part of the drillers, the ship's crew, the technicians, and the scientific party. Close cooperation between Glomar Challenger and Melville was also necessary. The 5 days of on-deck recording reaped scientific information which required many months to evaluate, and results are reported in several chapters in 


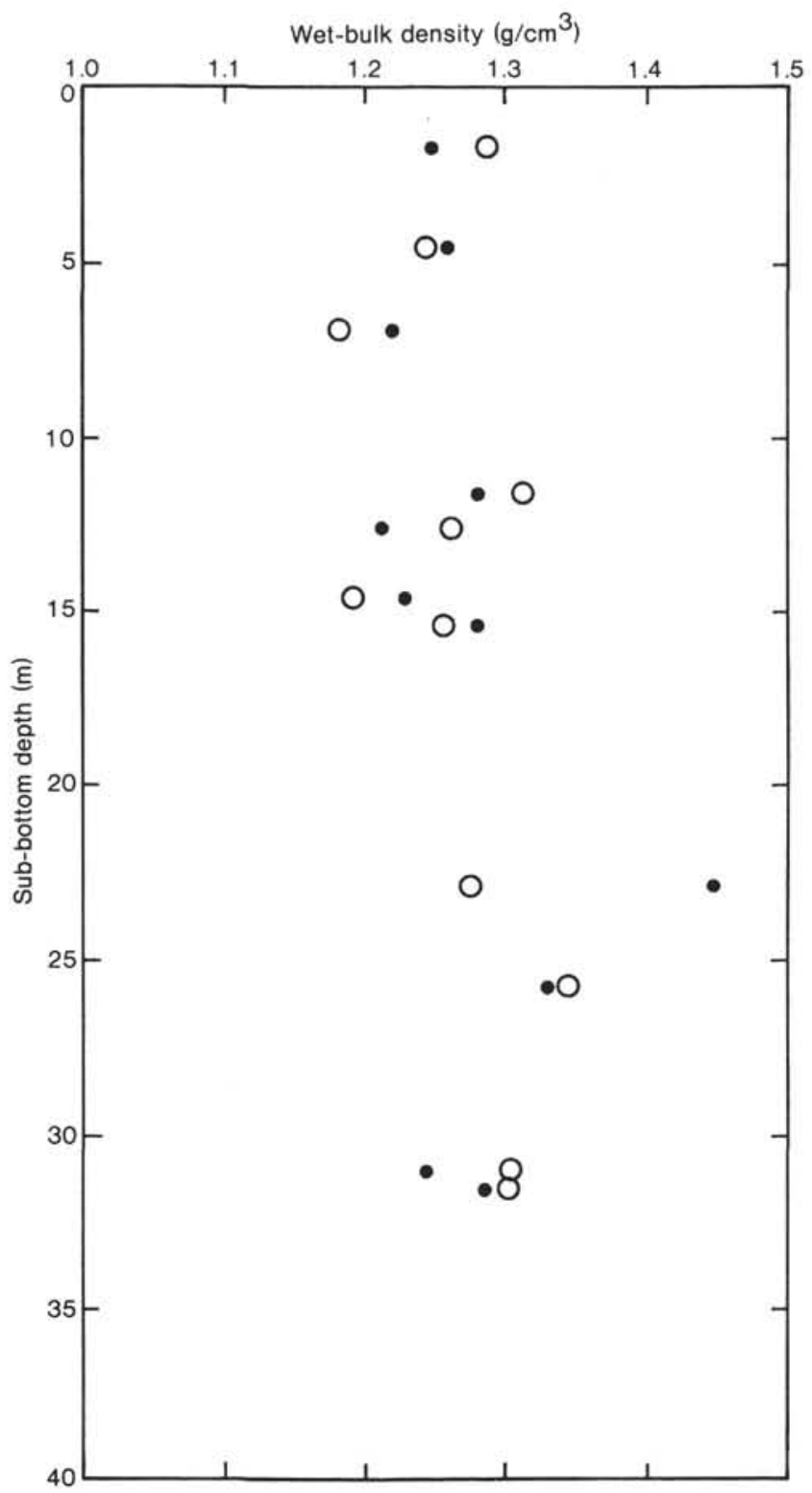

Figure 8. Wet-bulk density plotted versus depth for soft sediments cored in Holes 595A and 595B, measured by (O) GRAPE and ( ) gravimetric techniques.

this volume. Since these data were, in the fullest sense, the scientific objective of Leg 91, this Summary and Conclusions section, which is concerned with shipboard scientific results, is necessarily incomplete. What we can say is that most components of the BIP worked, and worked well, during the period of on-deck recording; that there was considerable overlap with Melville's seismic refraction experiment, but less overlap than originally was hoped; that a reasonable number of measurements of ambient noise were made with Glomar Challeng$e r$ 's thrusters silent; and that the BIP recorded many earthquakes, not all of them from the Tonga Trench. As Glomar Challenger left Site 595, all OBSs and the BPP were recording earthquake data on the seafloor. Some of the BPP capacity had been reduced by an electrical failure, but the most critical information was being recorded for comparison to the OBS data. The mooring system was in place for retrieval of the BPP, which was accomplished in April 1983.

From an operational perspective, although the entire deployment was complex, the most critical stages came early in the leg with the construction of the reentry cone structure on the seafloor. No previous reentry cone had been lowered to the seafloor in water so deep, with sediment cover so thin, and with the certain knowledge that cherts, always difficult to core, lay only $30 \mathrm{~m}$ beneath the seafloor. Only with the final core in the reentry hole, 595B, was there full lateral support for the bottom hole assembly of the drill string.

Once the reentry cone was set, and the hole drilled, however, the success of the operation depended more on the performance of various components of the MSS during the several stages of its deployment than on the capabilities of Glomar Challenger. At this point, Glomar Challenger was required primarily to lower equipment to the seafloor, to reenter the cone, to hold position, and to maneuver to new positions. Each of these tasks was exacting, but in good weather they were readily performed without great risk to equipment or the hole.

The most difficult problem with the MSS came with the first stages of lowering the BIP to the seafloor. An electrical short-circuit in the EM cable at its connection with the BIP required that the entire cable head be repotted to the backup BIP. This delayed the operation by more than 2 days, and was followed by an additional 17hr. delay for weather. Actually, the weather and sea state were more cooperative at this time than at any other, inasmuch as the highest winds and worst sea state of the leg occurred while the cable potting was setting up. Even had the seas been flat calm, nothing could have been done at this time.

These delays, however, had the only serious impact on the scientific results of the leg, cutting deeply into the programmed periods of simultaneous BIP-OBS recording of Melville's seismic refraction experiments. Regular radio communications with scientists on board Melville kept them apprised of our progress, and they carefully harbored their explosives and did as much as possibility to build flexibility into their program, eventually allowing about $50 \%$ of the planned BIP-OBS recording overlap to take place.

Following the on-deck recording, the remainder of the MSS deployment was surprisingly uneventful, although shifting the weight of the BPP from the ship's crane to the Pengo winch on the port side of the main deck was potentially hazardous and certainly interesting to watch. Sea state at this time, however, was about as calm as it ever became during the leg, and the transfer was accomplished without difficulty. Putting the installation retrieval and reinstallation mooring (IRR) into place took only about $30 \mathrm{hr}$. and, apart from consuming about a dozen fan belts on the Pengo winch, incurred no delays. Time still remained to piston core a reference sediment section nearby at Site 596.

A considerable side benefit of all this activity was the results of the coring. An unusual, albeit very thin, sedimentary sequence overlies basalt at Site 595 . The sequence 
Table 5. Water content cylinder data for Hole 595A. ${ }^{a}$

\begin{tabular}{|c|c|c|c|c|c|c|c|}
\hline $\begin{array}{l}\text { Sub-bottom } \\
\text { depth } \\
\text { (m) }\end{array}$ & $\begin{array}{c}\text { Core-Section } \\
\text { (interval in } \mathrm{cm} \text { ) }\end{array}$ & $\begin{array}{l}\text { Wet-bulk } \\
\text { density } \\
\left(\mathrm{g} / \mathrm{cm}^{3}\right)\end{array}$ & $\begin{array}{c}\text { Wet water } \\
\text { content } \\
(\%)\end{array}$ & $\begin{array}{c}\text { Dry water } \\
\text { content } \\
(\%)\end{array}$ & $\begin{array}{l}\text { Porosity } \\
\left(\mathrm{g} / \mathrm{cm}^{3}\right)\end{array}$ & $\begin{array}{l}\text { Void } \\
\text { ratio }\end{array}$ & $\begin{array}{l}\text { Grain } \\
\text { density } \\
\left(\mathrm{g} / \mathrm{cm}^{3}\right)\end{array}$ \\
\hline \multicolumn{8}{|c|}{ Uncorrected for salt content } \\
\hline 0.19 & $1-1,18-21$ & 1.27 & 66.1 & 195 & 83.9 & 5.23 & 2.68 \\
\hline 1.70 & $1-2,19-22$ & 1.25 & 68.7 & 219 & $86 / 2$ & 6.27 & 2.85 \\
\hline 4.62 & $2-2,31-34$ & 1.26 & 66.0 & 198 & 82.8 & 4.81 & 2.48 \\
\hline 6.98 & $2-3,117-120$ & 1.22 & 71.0 & 245 & 86.4 & 6.33 & 2.58 \\
\hline 11.63 & $2-6,132-135$ & 1.28 & 68.9 & 177 & 81.9 & 4.54 & 2.50 \\
\hline 12.66 & $3-1,45-48$ & 1.21 & 68.9 & 221 & 83.3 & 4.99 & 2.25 \\
\hline 14.64 & $3-2,93-96$ & 1.23 & 68.3 & 215 & 83.8 & 5.18 & 2.40 \\
\hline 15.46 & $3-3,25-28$ & 1.28 & 62.8 & 168 & 80.5 & 4.12 & 2.44 \\
\hline 23.15 & $4-1,136-138$ & 1.27 & 64.6 & 182 & 82.2 & 4.61 & 2.53 \\
\hline 25.88 & $4-3,107-110$ & 1.33 & 60.7 & 154 & 80.7 & 4.18 & 2.70 \\
\hline 31.11 & $4-7,30-33$ & 1.24 & 65.3 & 189 & 81.1 & 4.30 & 2.29 \\
\hline 31.60 & $5-1,20-23$ & 1.28 & 65.0 & 185 & 83.2 & 4.94 & 2.66 \\
\hline \multicolumn{8}{|c|}{ Corrected for salt content } \\
\hline 0.19 & $1-1,18-21$ & 1.27 & 68.5 & 202 & 87.0 & 6.68 & 3.30 \\
\hline 1.70 & $1-2,19-22$ & 1.25 & 71.2 & 227 & 89.4 & 8.40 & 3.69 \\
\hline 4.62 & $2-2,31-34$ & 1.26 & 68.4 & 200 & 85.8 & 6.04 & 3.01 \\
\hline 6.98 & $2-3,117-120$ & 1.22 & 73.6 & 254 & 89.5 & 8.51 & 3.35 \\
\hline 11.63 & $2-6,132-135$ & 1.28 & 66.3 & 183 & 84.9 & 5.63 & 3.07 \\
\hline 12.66 & $3-1,45-48$ & 1.21 & 71.4 & 229 & 86.3 & 6.31 & 2.74 \\
\hline 14.64 & $3-2,93-96$ & 1.23 & 70.8 & 223 & 86.9 & 6.62 & 3.96 \\
\hline 15.46 & $3-3,25-28$ & 1.28 & 65.1 & 175 & 83.4 & 5.02 & 2.07 \\
\hline 23.15 & $4-1,136-138$ & 1.27 & 66.9 & 189 & 85.2 & 5.74 & 3.04 \\
\hline 25.88 & $4-3,107-110$ & 1.33 & 62.9 & 160 & 83.6 & 5.10 & 3.18 \\
\hline 31.11 & $4-7,30-33$ & 1.24 & 67.7 & 195 & 84.1 & 5.29 & 2.71 \\
\hline 31.60 & $5-1,20-23$ & 1.28 & 67.3 & 192 & 86.2 & 6.23 & 3.24 \\
\hline
\end{tabular}

was divided into two subunits, the upper one consisting of $40 \mathrm{~m}$ of pelagic clay, and the lower one $30 \mathrm{~m}$ of pelagic clay interbedded with cherts and porcellanites. As the entire sequence was more carefully cored at Site 596, where recovery was greater and disturbance less, and as the sediments there were divided into more units, discussion of the sediments is deferred to the Site 596 report.

The remaining coring was in two holes, 595A and 595B, in basement. Three petrographically distinct lava types were cored, each consisting of pillows and/or thin flows with fine-grained or glassy chill margins. The lavas are virtually aphyric and are identified petrographically as (1) mainly massive olivine tholeiite, (2) tholeiitic ferrobasalt pillows, and (3) variolitic olivine tholeiite pillows, in order of depth. The presence of this range of lava types, including some ferrobasalts, is consonant with the distribution of similar lavas on rapidly spreading but not slowly spreading ridges.

An important feature of the lavas is their alteration. They are highly fractured, and along the fractures are multiple sequences of cross-cutting vein minerals. These are iron and manganese oxyhydroxides, green clays, and carbonates (both calcite and aragonite). Paralleling veins with iron oxyhydroxides are dark alteration halos in which iron oxyhydroxides are concentrated along tiny fractures in the rock. Many of these tiny fractures are microscopic in scale, crossing individual grains of plagioclase and clinopyroxene in the rock.

The uppermost olivine tholeiite did not experience the earliest stages of alteration evident in the deeper rocks.
The first stages of alteration of the deeper rocks thus were at or near the spreading axis, and occurred prior to eruption of the upper olivine tholeiite. Each episode of alteration was preceded or accompanied by widening of previous fractures and formation of new ones. Only the extensive calcite veining, which occurred late in the alteration sequence, and a final stage of pervasive transformation of groundmass glass and minerals to a pale yellow clay, acted to seal and condition the crust, permitting relatively easy basement coring at Site 595 . The basalts at Site 595 are among the first ever recovered from crust produced at a rapidly spreading ridge in which the sequence of veining and alteration can be worked out with some care. This is because here, vein minerals were not destroyed by the drilling process, as they typically have been in rocks drilled in young crust near rapidly spreading ridges. On the basis of the Site 595 basement coring, the recovery seems sufficiently good to recommend that future sites be drilled in old crust in the Pacific, in order to understand processes acting at the axes of rapidly spreading ridges.

\section{REFERENCES}

American Society for Testing and Materials, 1967. 1967 Book of A.S.T.M. Standards, Part II: Philadelphia (A.S.T.M.).

Bass, M. N., 1973. Rare and unusual minerals and fossils (?) in sediments of Leg 34. In Yeats, R. S., Hart, S. R., et al., Init. Repts. DSDP, 34: Washington (U.S. Govt. Printing Office), 611-624.

Bennett, R. H., and Keller, G. H., 1973. Physical properties evaluation. In van Andel, T. H., Heath, G. R., et al., Init. Repts. DSDP, 16: Washington (U.S. Govt. Printing Office), 513-519. 
Boström, K., and Peterson, M. N. A., 1966. Precipitates from hydrothermal exhalations on the East Pacific Rise, Econ. Geol., 61: 12581265.

Boyce, R. E., 1973. Appendix I. Physical properties methods. In Edgar, N.T., Saunders, J. B., et al., Init. Repts. DSDP, 15: Washington (U.S. Govt. Printing Office), 1115-1127.

1976. Definition and laboratory technique of compressional sound velocity parameters and wet-water content, wet-bulk density, and porosity parameters by gravimetric and gamma-ray attenuation technique. In Schlanger, S. O., Jackson, E. D., et al., Init. Repts. DSDP, 33: Washington (U.S. Govt. Printing Office), 931951.

1977. Deep-Sea Drilling Project procedures for shear strength measurements of clay sediment using modified Wukeham Farrance laboratory wave apparatus. In Barker, P. F., Dalziel, I. W. D., et al., Init. Repts. DSDP, 36: Washington (U.S. Govt. Printing Office), 1059-1068.

Corliss, J. B., Lule, M., Dymond, J. R., and Crane, K., 1978. The chemistry of hydrothermal sediment mound deposits near the Galapagos Rift. Earth Planet. Sci. Lett., 40: 12-24.

Demars, K. R., and Nacci, V. A., 1978. Significance of Deep-sea Drilling Project sediment physical property data. Mar. Geotechnol., 3: 151-170.

Einsele, G., 1982. Mass physical properties of Pliocene to Quaternary sediments in the Gulf of California, Deep Sea Drilling Project Leg 64. In Curray, J. R., Moore, D. G., et al., Init. Repts. DSDP, 64: Washington (U.S. Govt. Printing Office), 529-542.

Evans, H. B., and Cotterell, C. H., 1970. Gamma ray attenuation density scanner. In Peterson, M. N. A., Edgar, N. T., et al., Init. Repts. DSDP, 2: Washington (U.S. Govt. Printing Office), 442-454.

Hekinian, R., Rosendahl, B. R., and Natland, J. H., 1980. Ocean crust geothermal processes: a perspective from the vantage of Leg 54 drilling. In Rosendahl, B. R., Hekinian, R., et al., Init. Repts. DSDP, 54: Washington (U.S. Govt. Printing Office), 395-422.
Houtz, R. E., and Ludwig, W. J., 1979. Distribution of reverberant subbottom layers in the southwest Pacific Basin. J. Geophys. Res., 84: 3497-3504.

Johnson, H. P., and Hall, J. M., 1978. A detailed rock magnetic and opaque mineralogy study of basalts from the Nazca plate. Geophys. J. R. Astron. Soc., 52: 45-64.

Natland, J. H., 1980. Effect of axial magma chambers beneath spreading centers on the compositions of basaltic rocks. In Rosendahl, B R., Hekinian, R., et al., Init. Repts. DSDP, 54: Washington (U.S. Govt. Printing Office), 833-850.

Perfit, M. R., and Fornari, D. J., 1983. Geochemical studies of abyssal lavas recovered by DSRV Alvin from the eastern Galapagos rift, Inca transform, and Ecuador rift, 2. Phase chemistry and crystallization history. J. Geophys. Res., 88: 10,530-10,550.

Prell, W. L., Gardner, J. V., et al., 1982. Leg 68: Introduction, explanatory notes, and conventions. In Prell, W. L., Gardner, J. V., et al., Init. Repts. DSDP, 68: Washington (U.S. Govt. Printing Office), 5-13.

Quilty, P. G., Sachs, H., Benson, W. E., Vallier, T. L., and Blechschmidt, G., 1973. Sedimentologic history, Leg 34, Deep Sea Drilling Project. In Yeats, R. S., Hart, S. R., et al., Init. Repts. DSDP, 34: Washington (U.S. Govt. Printing Office), 779-794.

Shephard, L. E., Bryant, W. R., and Chiou, W. A., 1982. Geotechnical properties of Middle America Trench sediments, Deep Sea Drilling Project Leg 66. In Watkins, J. S., Moore, J. C., et al., Init. Repts. DSDP, 66: Washington (U.S. Govt. Printing Office), 475504.

Von Herzen, R. P., and Maxwell, A. E., 1959. The measurement of thermal conductivity of deep-sea sediments by a needle-probe method. J. Geophys. Res., 64:1557-1563.

Walker, D., Shibata, T., and DeLong, S. E., 1979. Abyssal tholeiites from the Oceanographer fracture zone II. Phase equilibria and mixing. Contrib. Mineral. Petrol., 70: 111-125. 


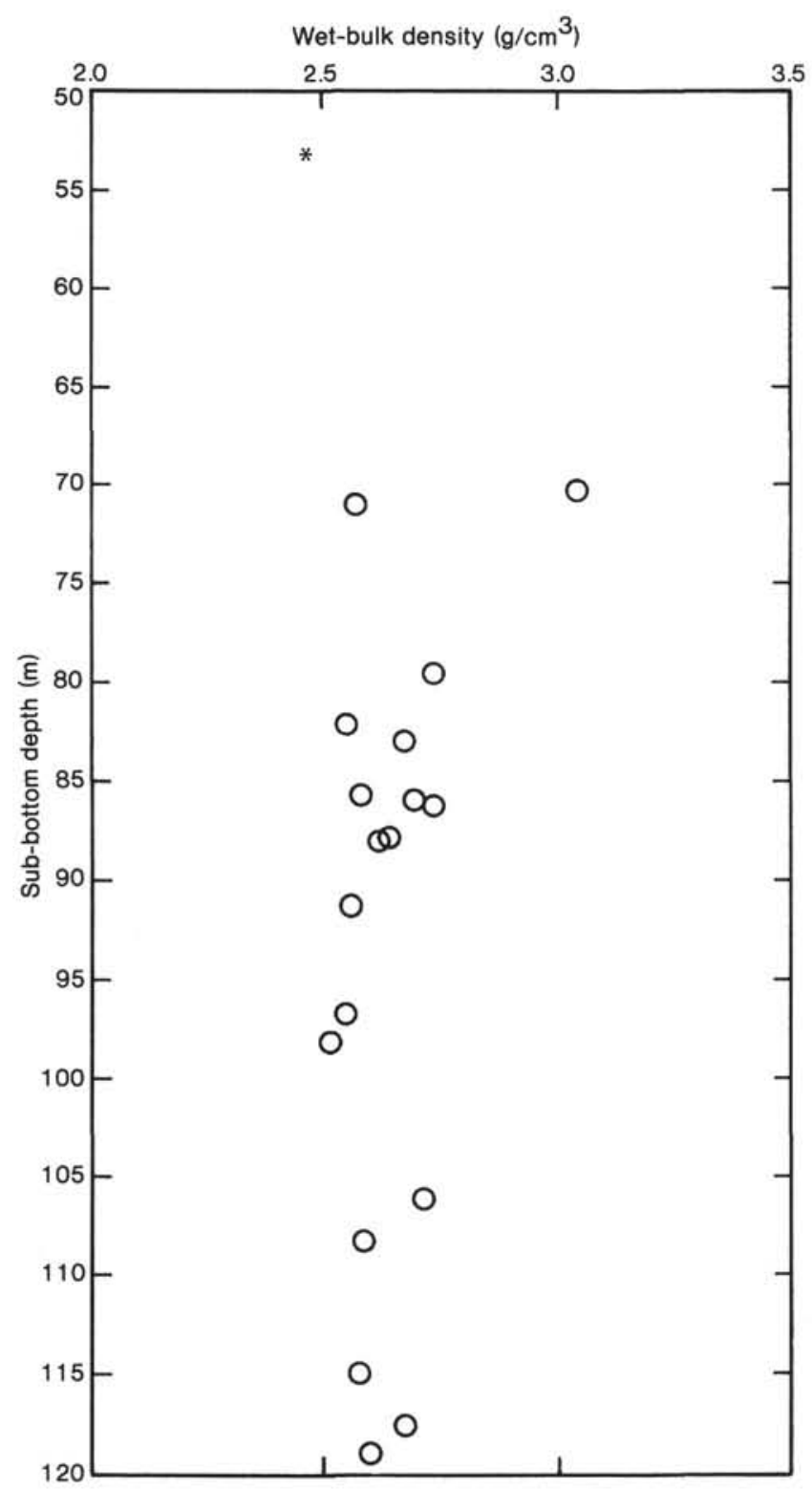

Figure 9 . Wet-bulk density plotted for $(O)$ basalts and (*) cherts, Holes 595A and 595B. 


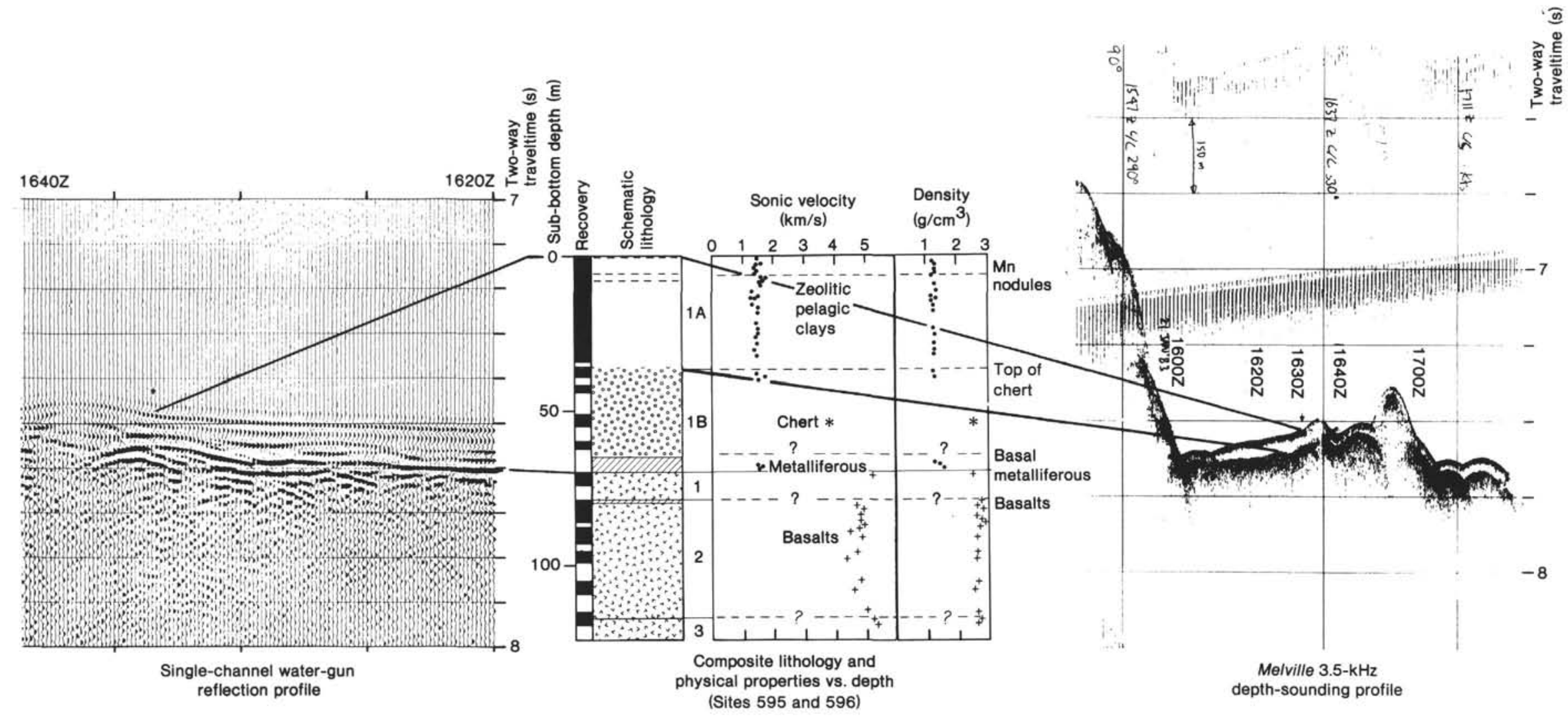

Figure 10. Correlation of physical properties and sediment lithology with water-gun reflection data (left) and 3.5-kHz sounding data (right). Reflections off the chert layer and the top of the ocean crust are seen in the reflection data, but only the chert reflection is seen in the $3.5-\mathrm{kHz}$ data. The chert reflection was interpreted by Glomar Challenger as the basement reflection, therefore explaining Glomar Challenger's much shallower sediment-thickness prediction at the site. (From Kim et al., this volume.) 

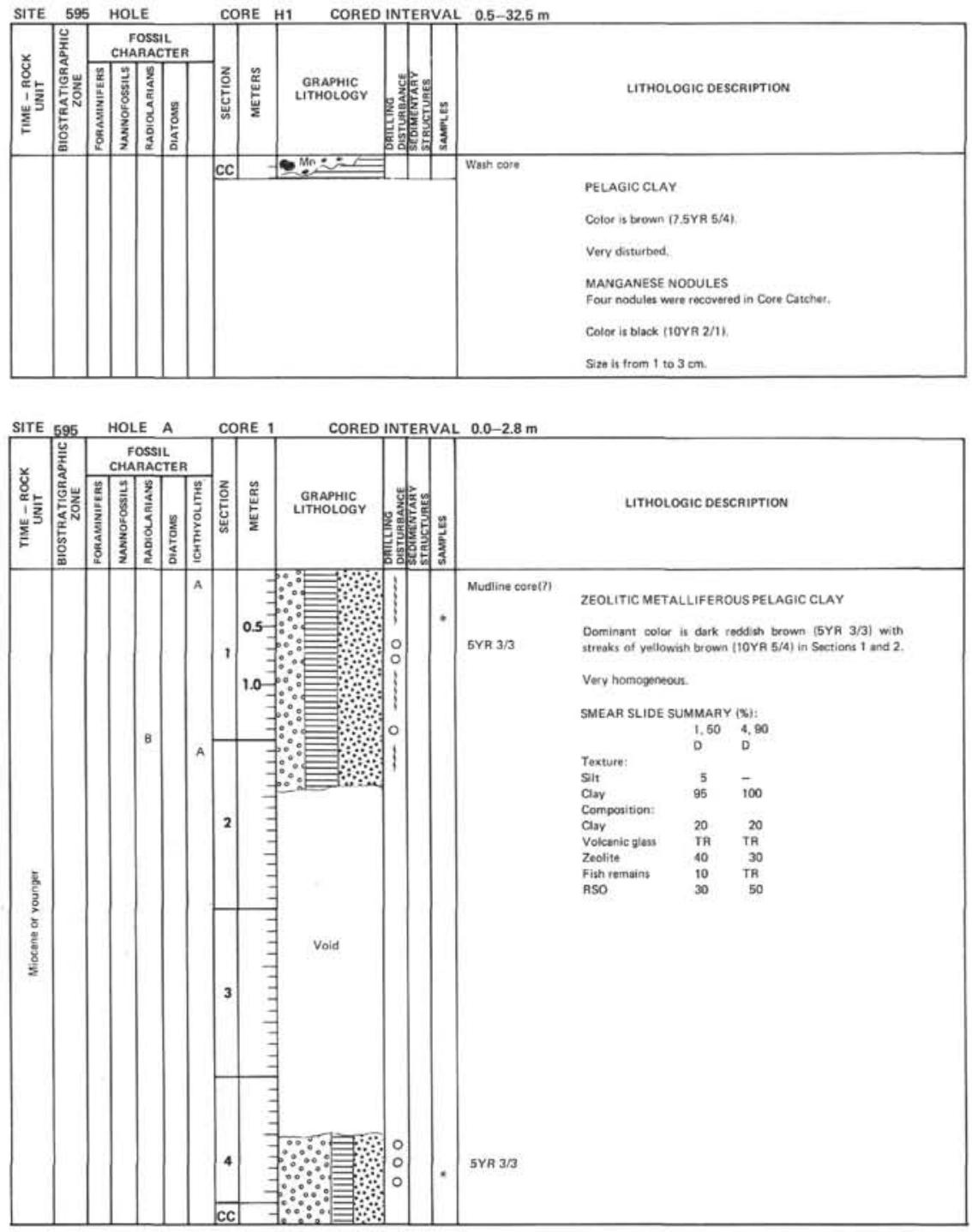

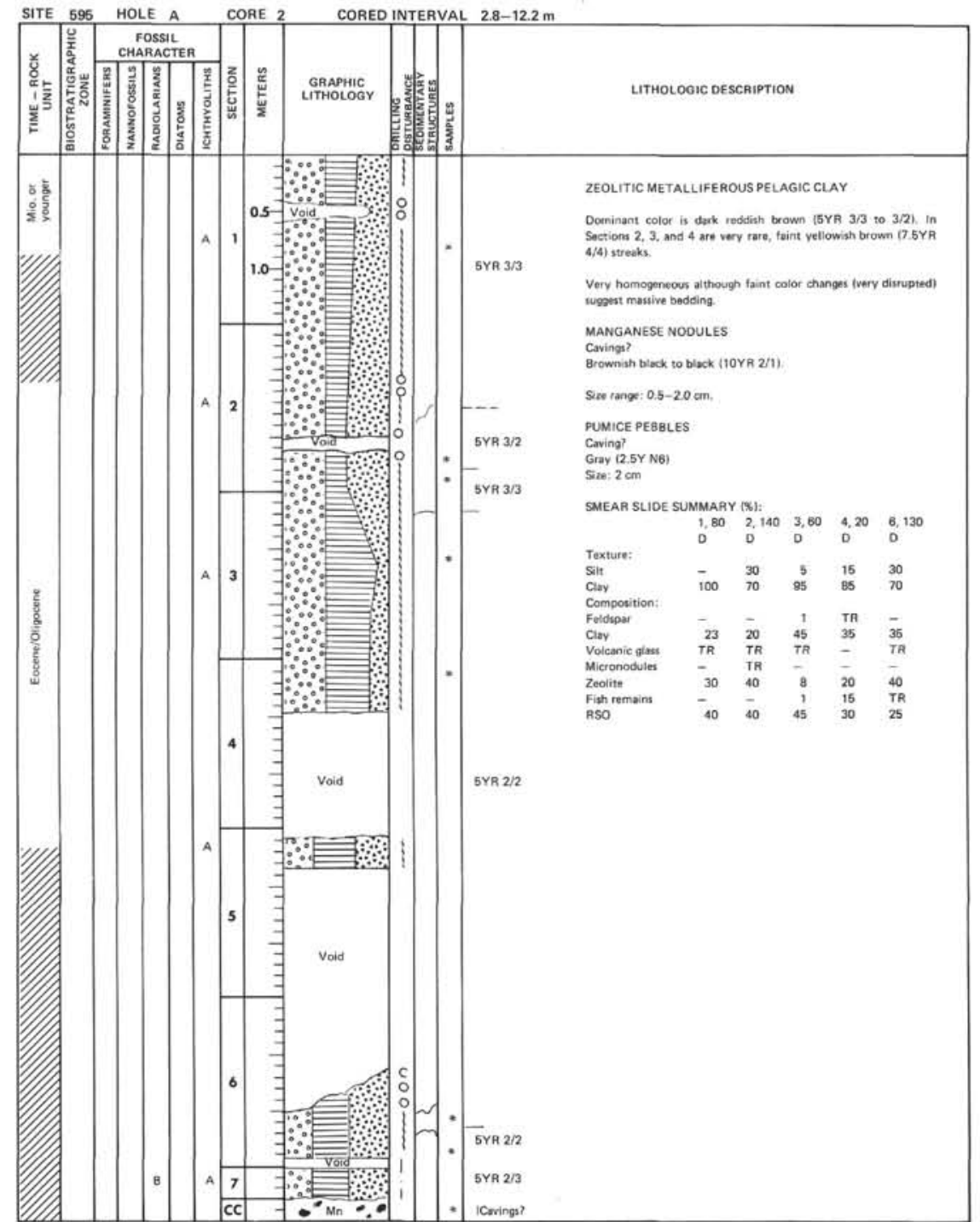



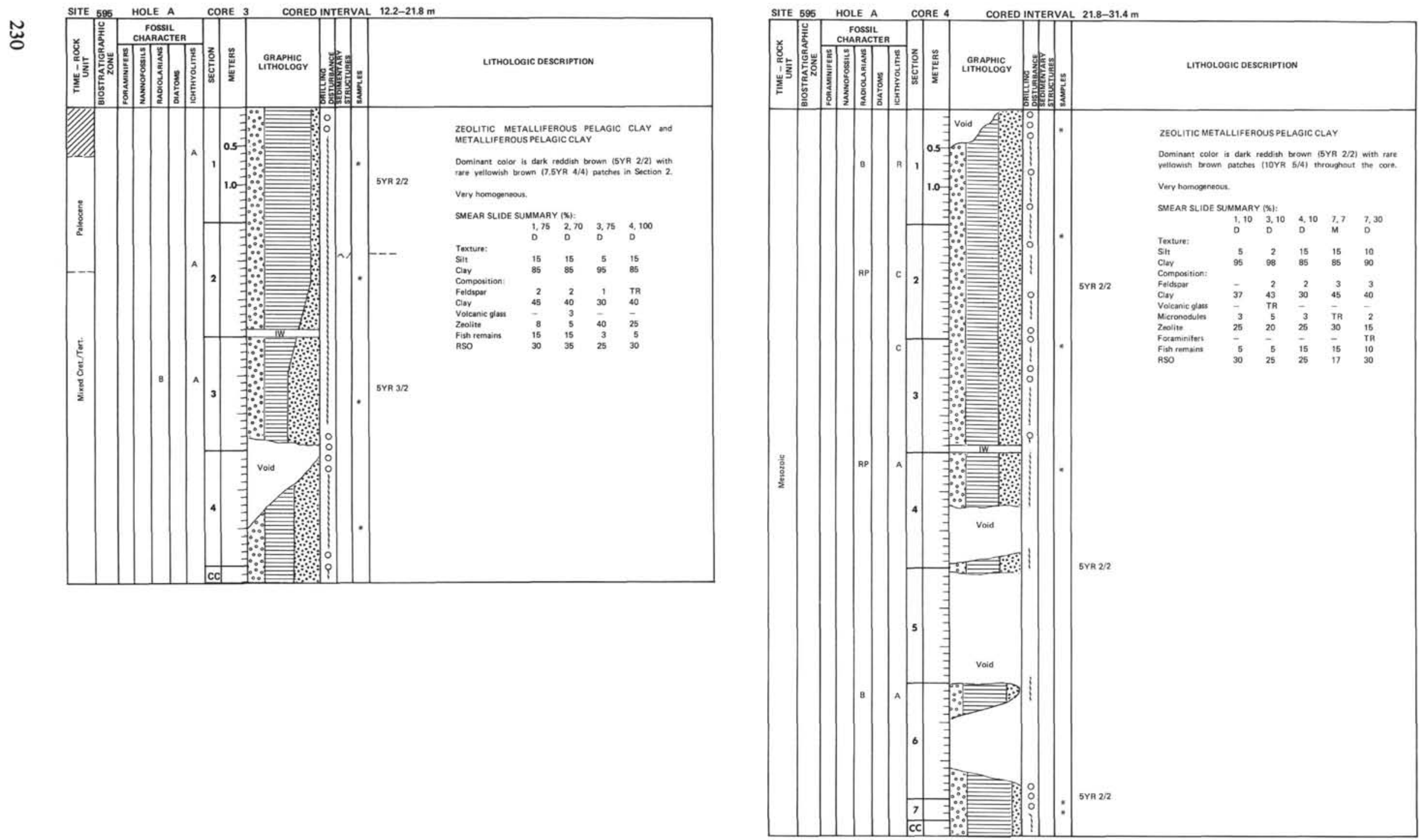

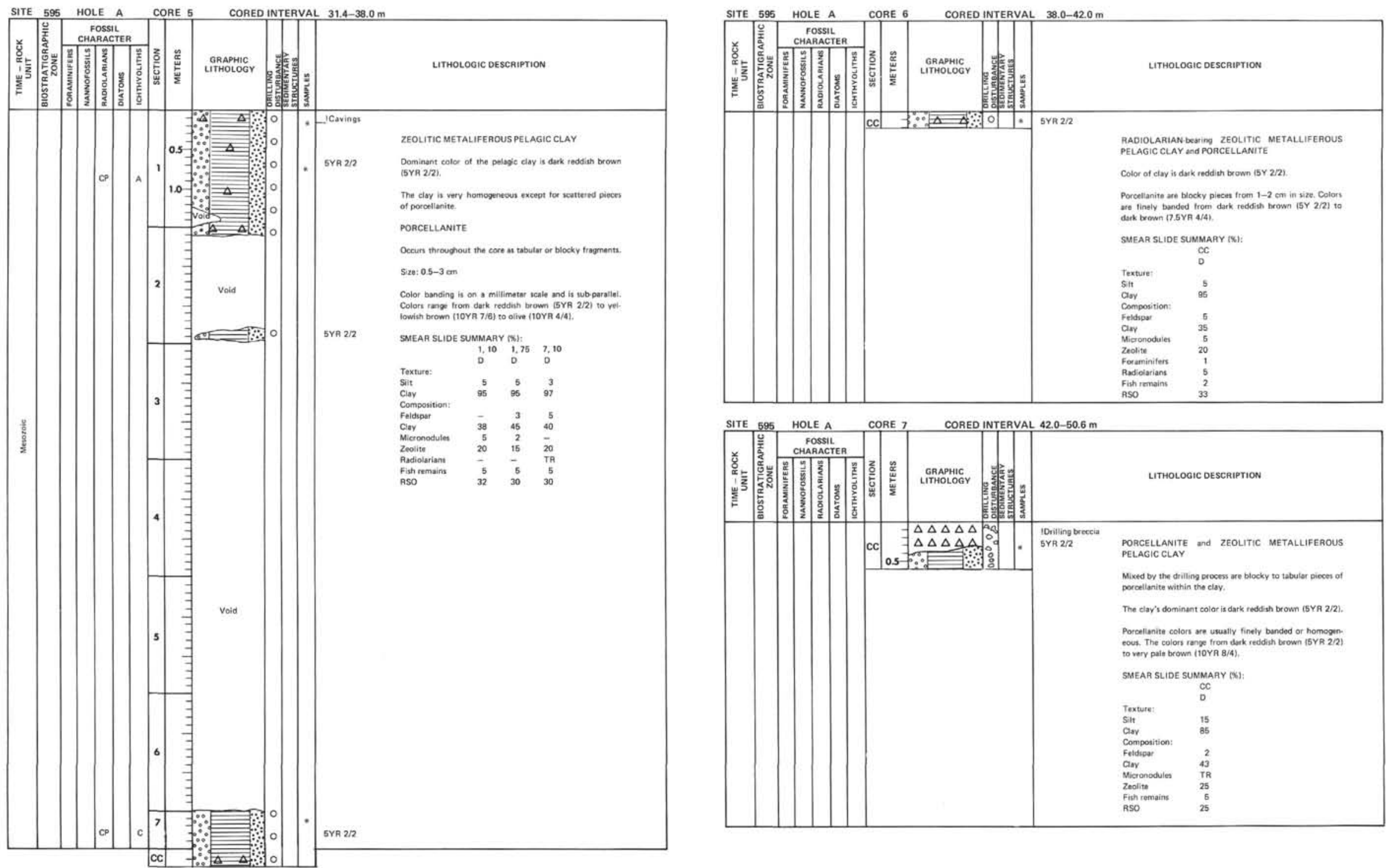


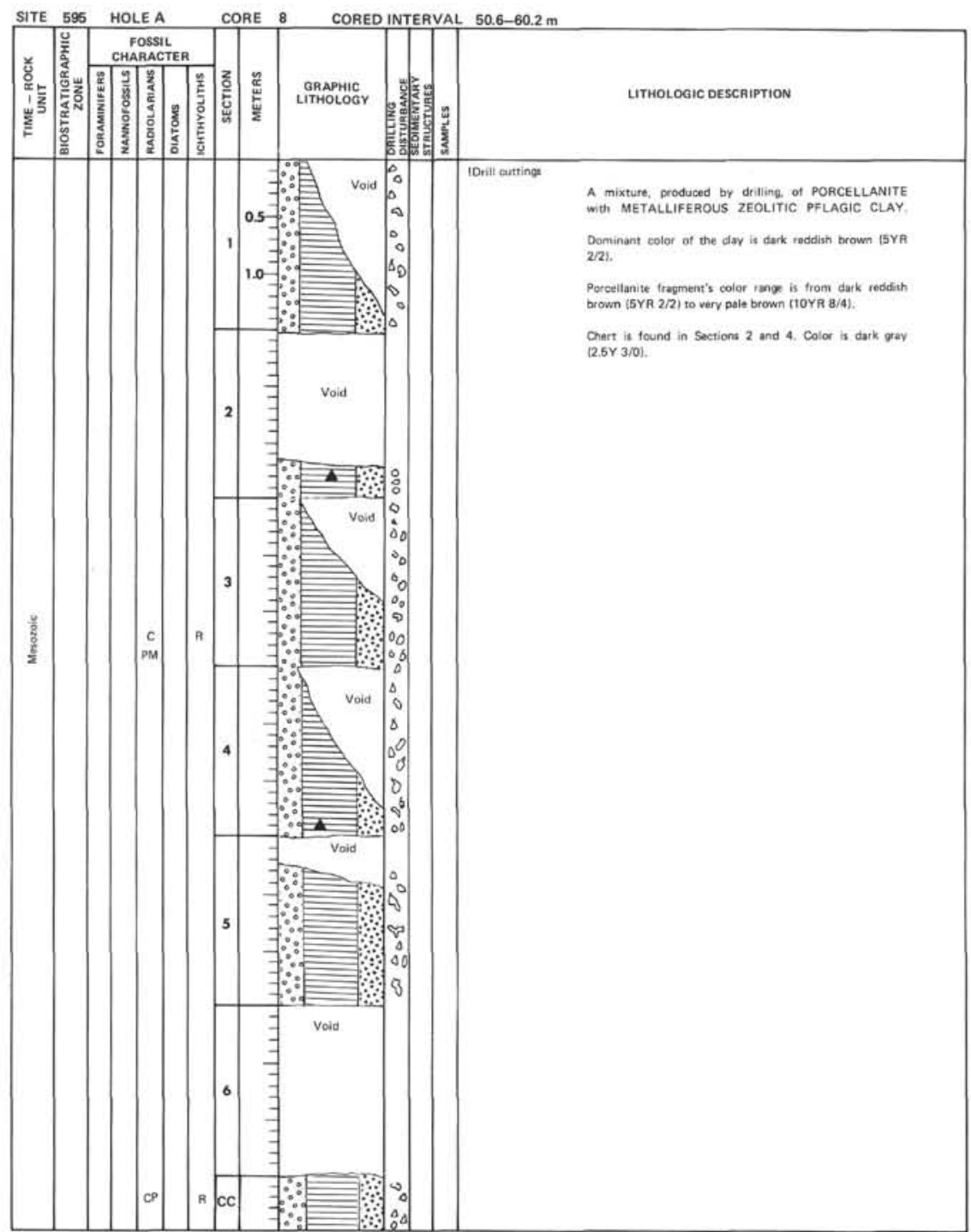

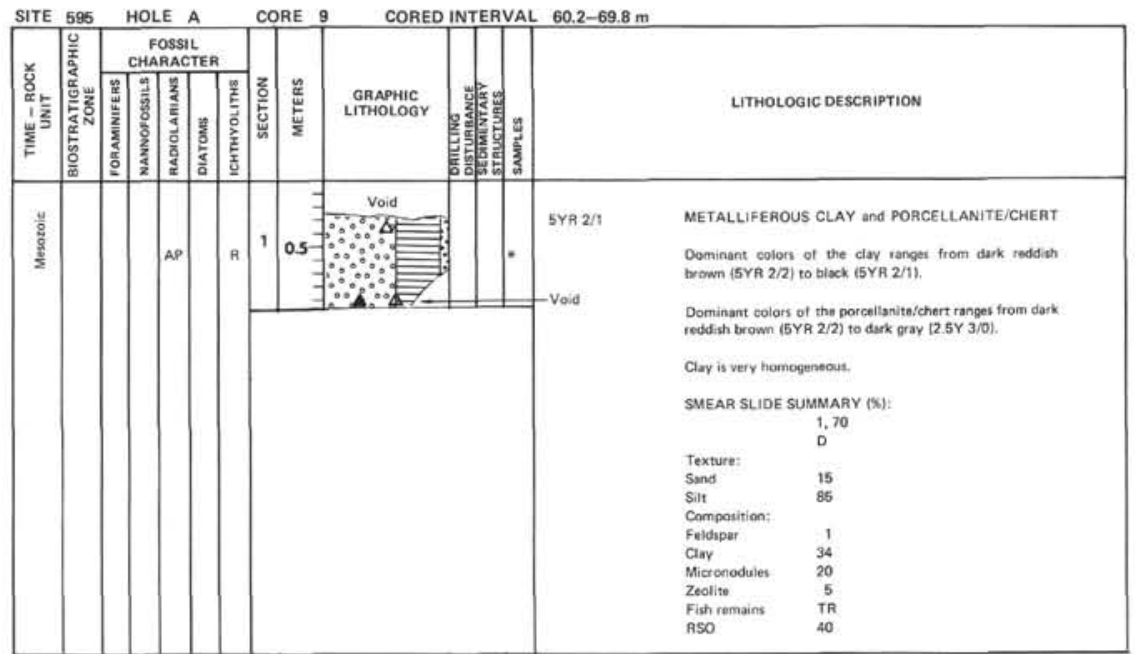




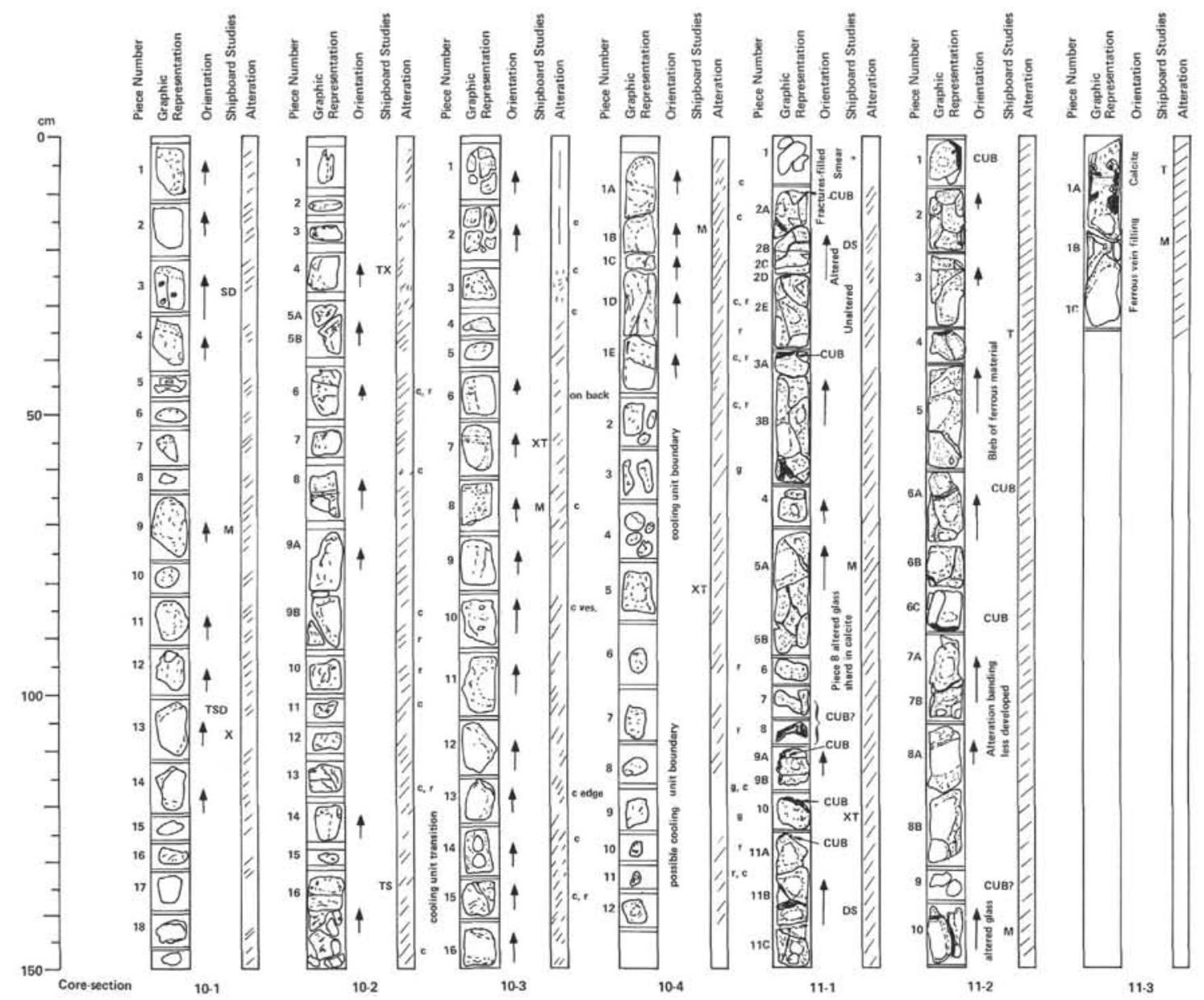

General dececistion Coret 10.

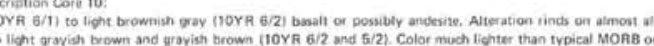

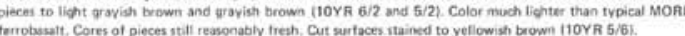

No glass prese
binocaulas soope

emptr
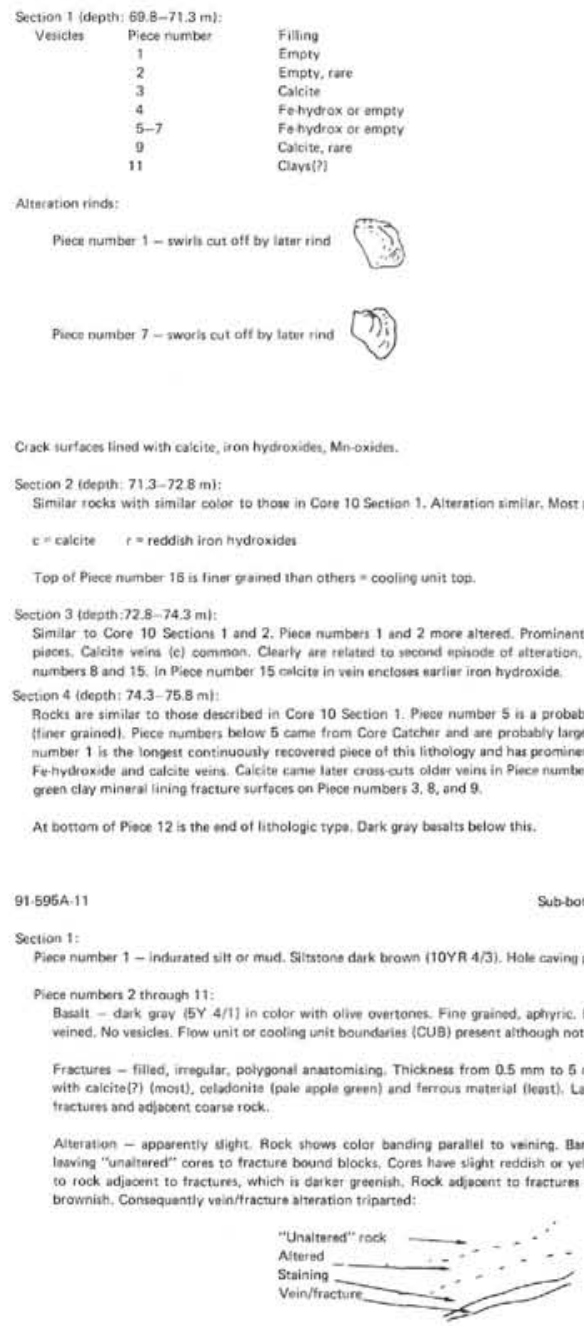

Section $2:$
Similar in

Section 3 :
signiar in 


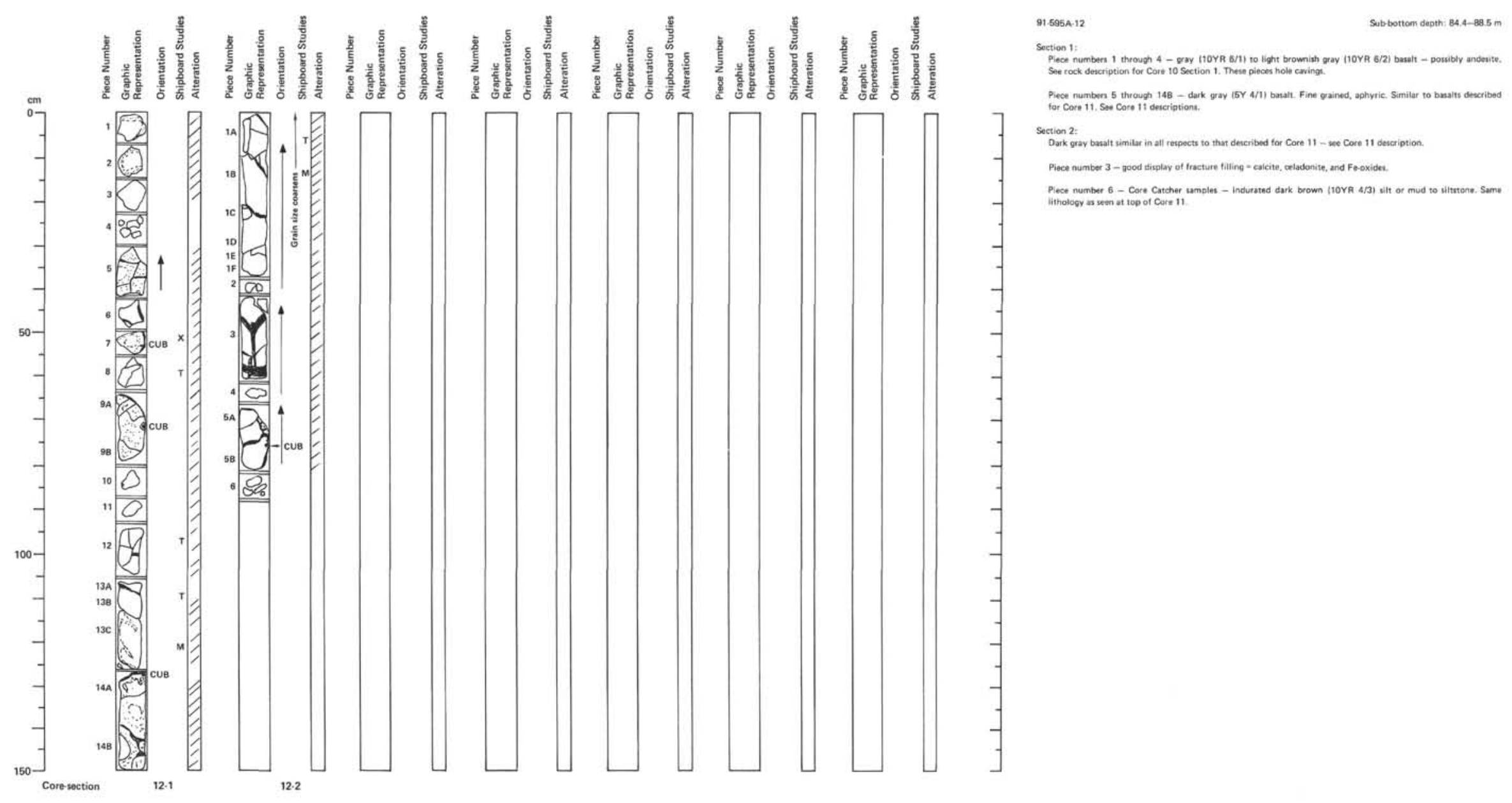



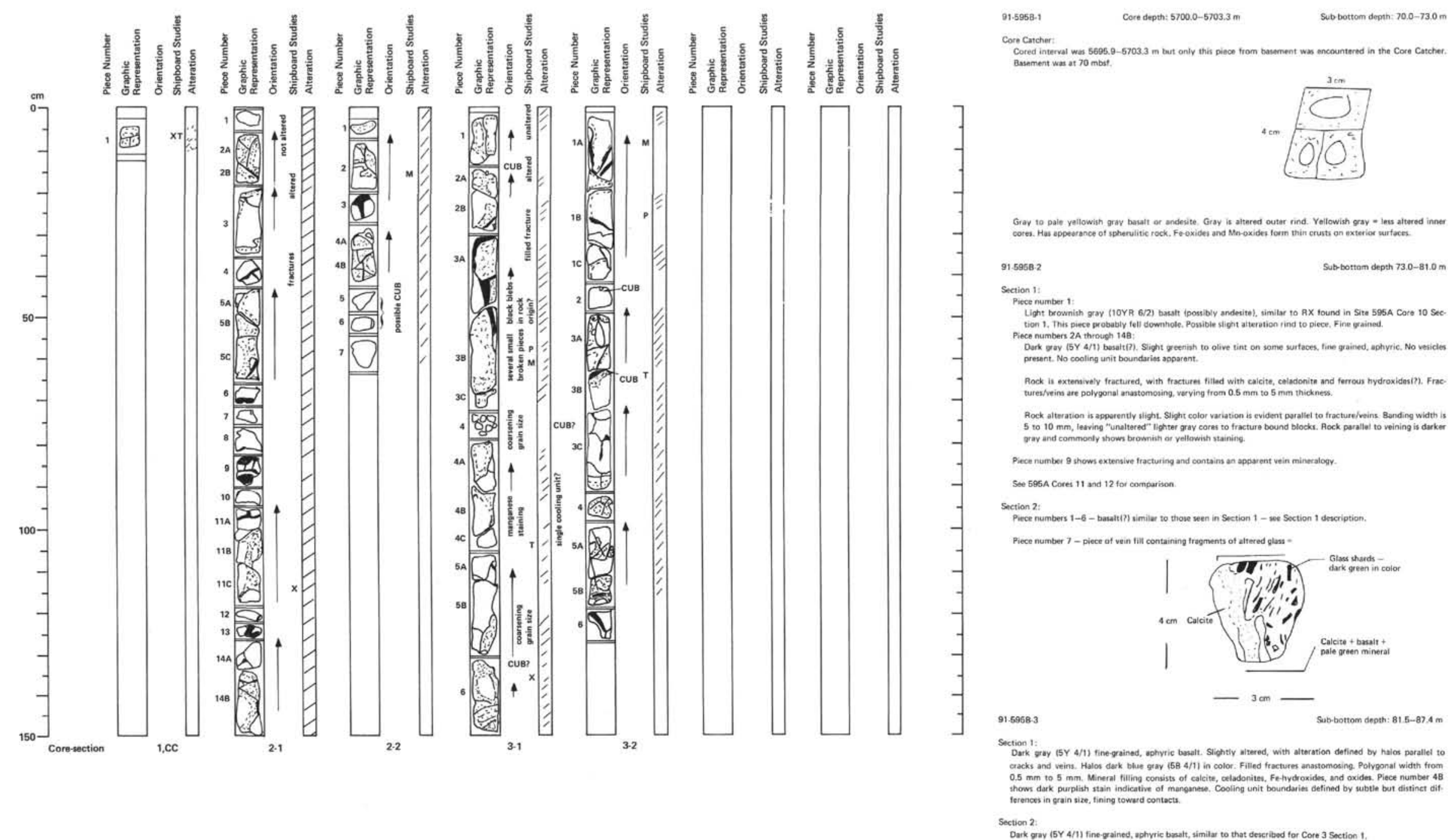


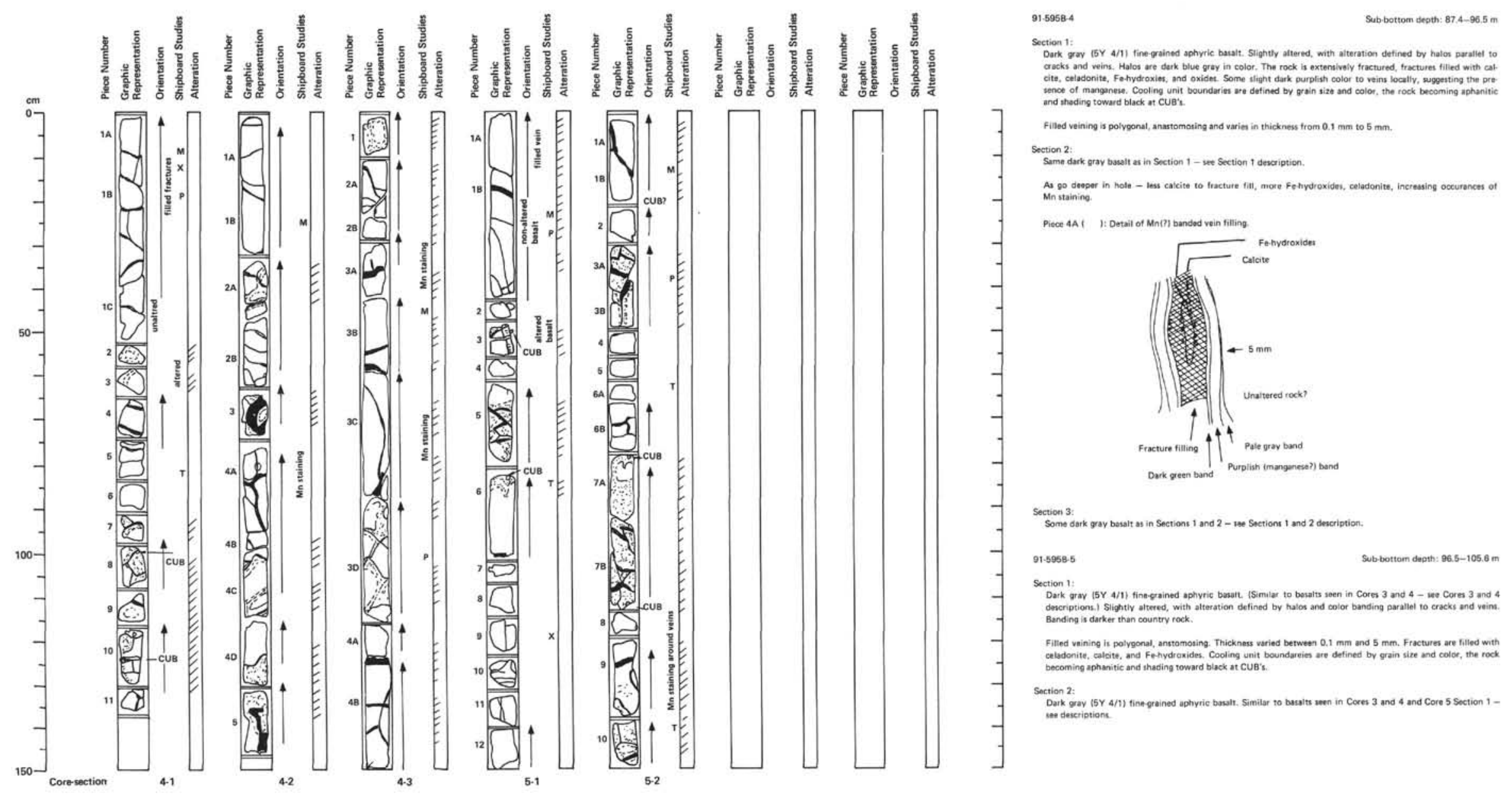




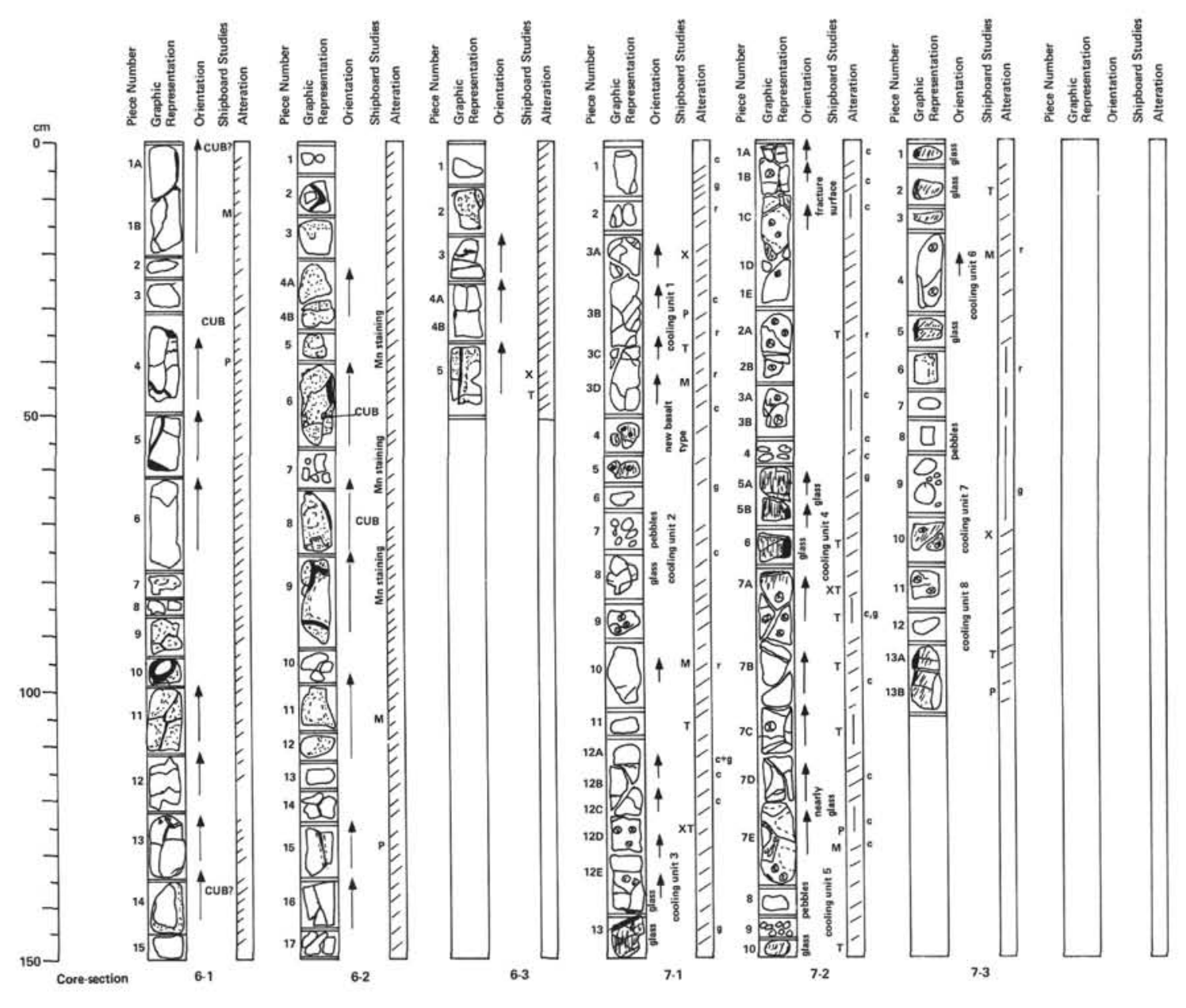

91.595

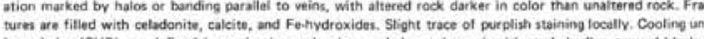

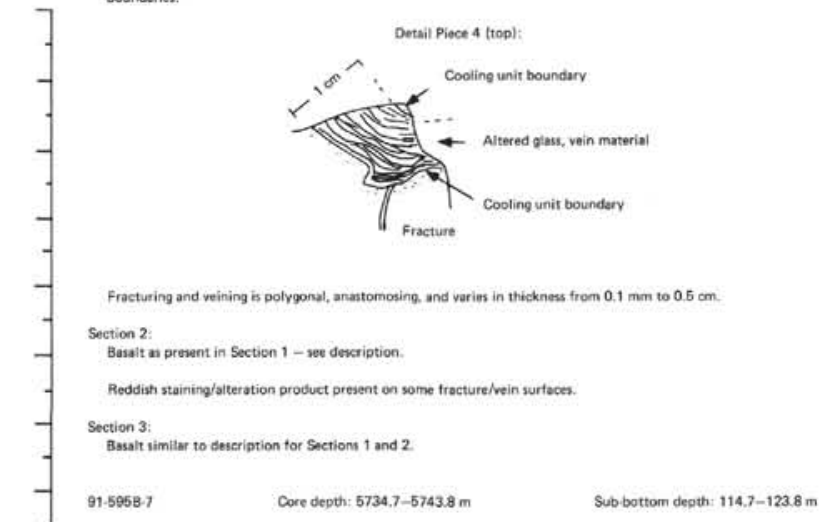

91.5958-7

Core depth: $5734.7-5743.8 \mathrm{~m}$

Sub bottom degth: $114.7-123.8 \mathrm{~m}$

Section 1

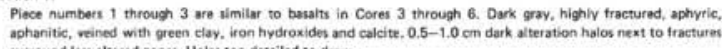

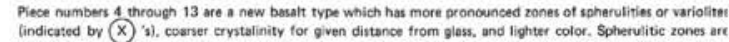

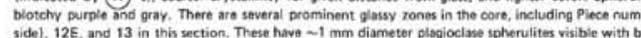

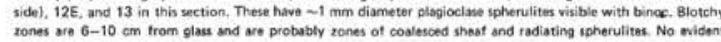
oivives, attered or othermse

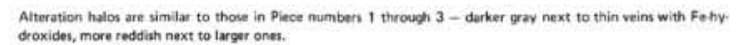

Nour:

Soction 2

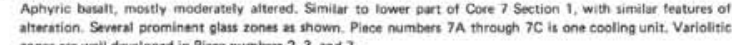
developed in Piece numbers 2,3 , nnd 7.

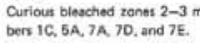

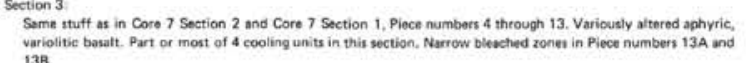


SITE 595 (HOLE 595)

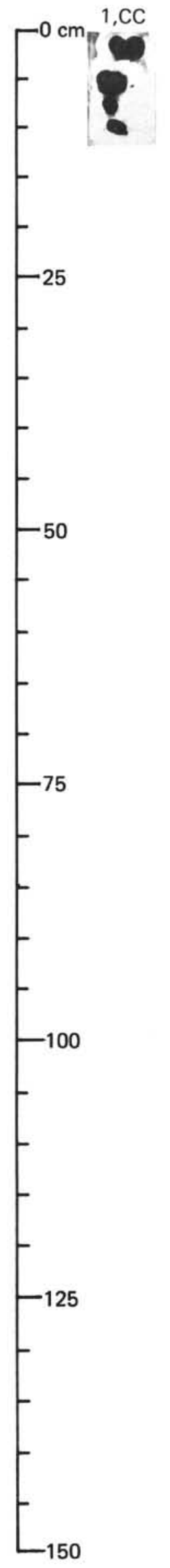

238 
SITE 595 (HOLE 595A)

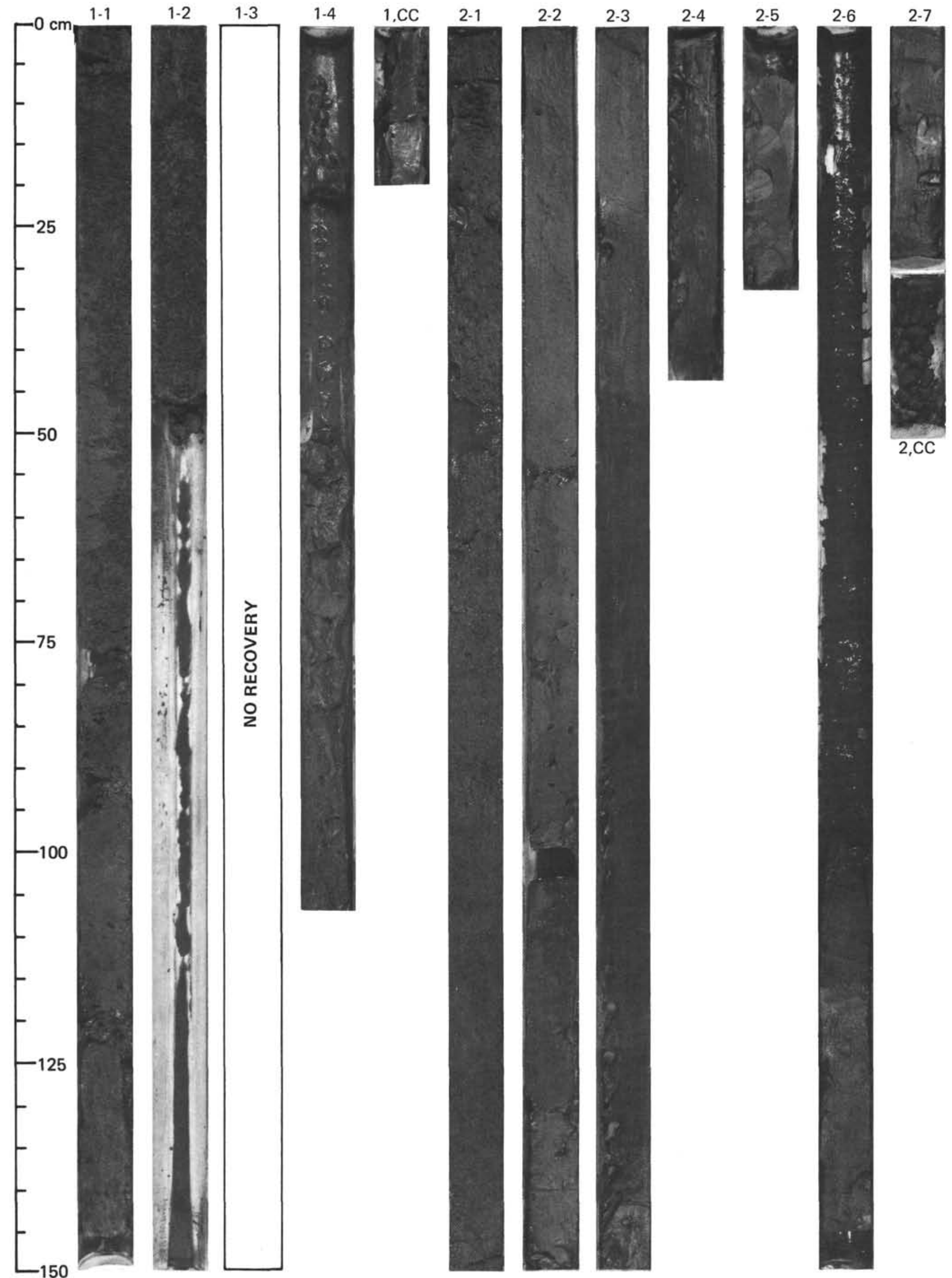


SITE 595 (HOLE 595A)

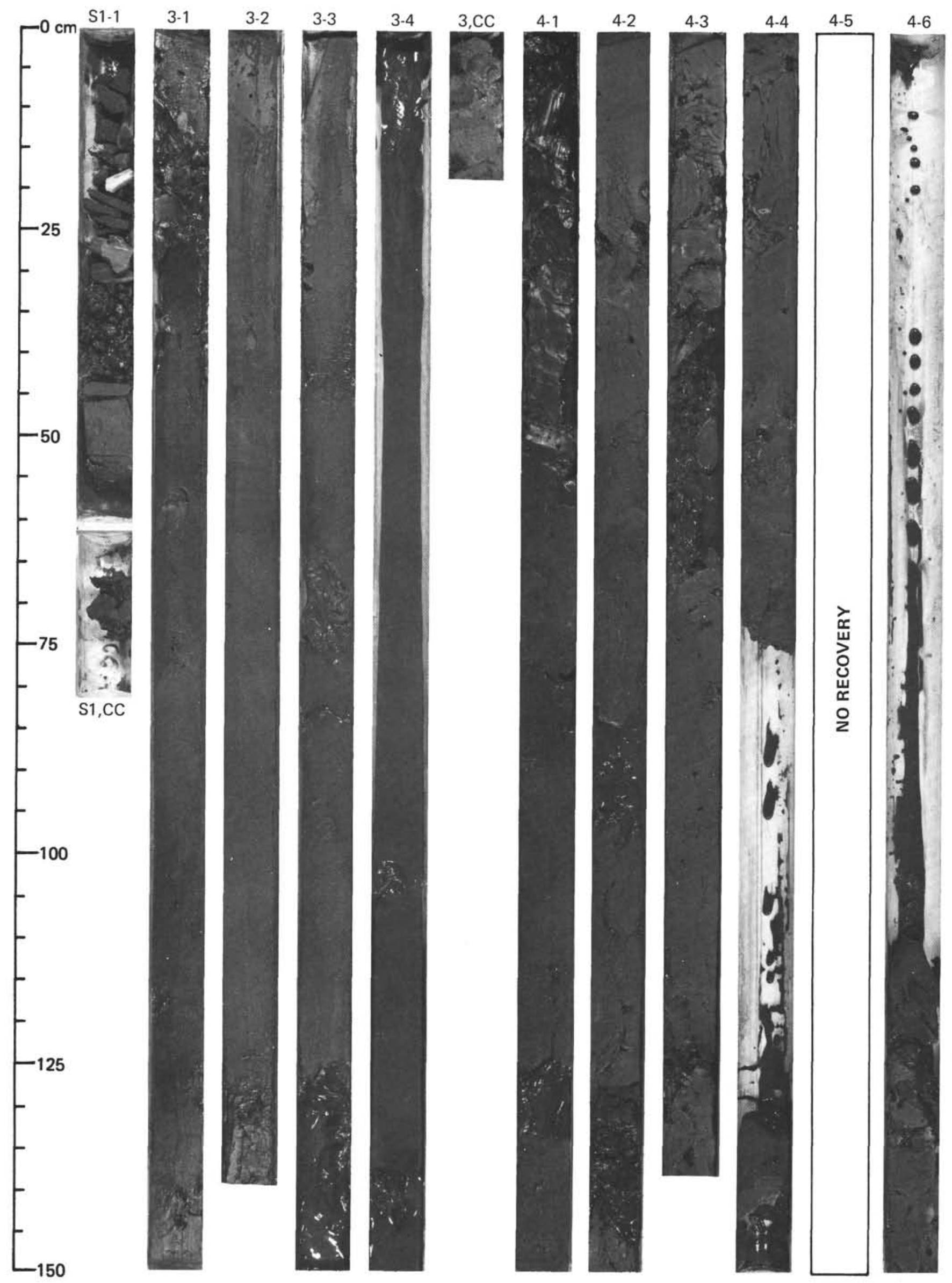


SITE 595 (HOLE 595A)

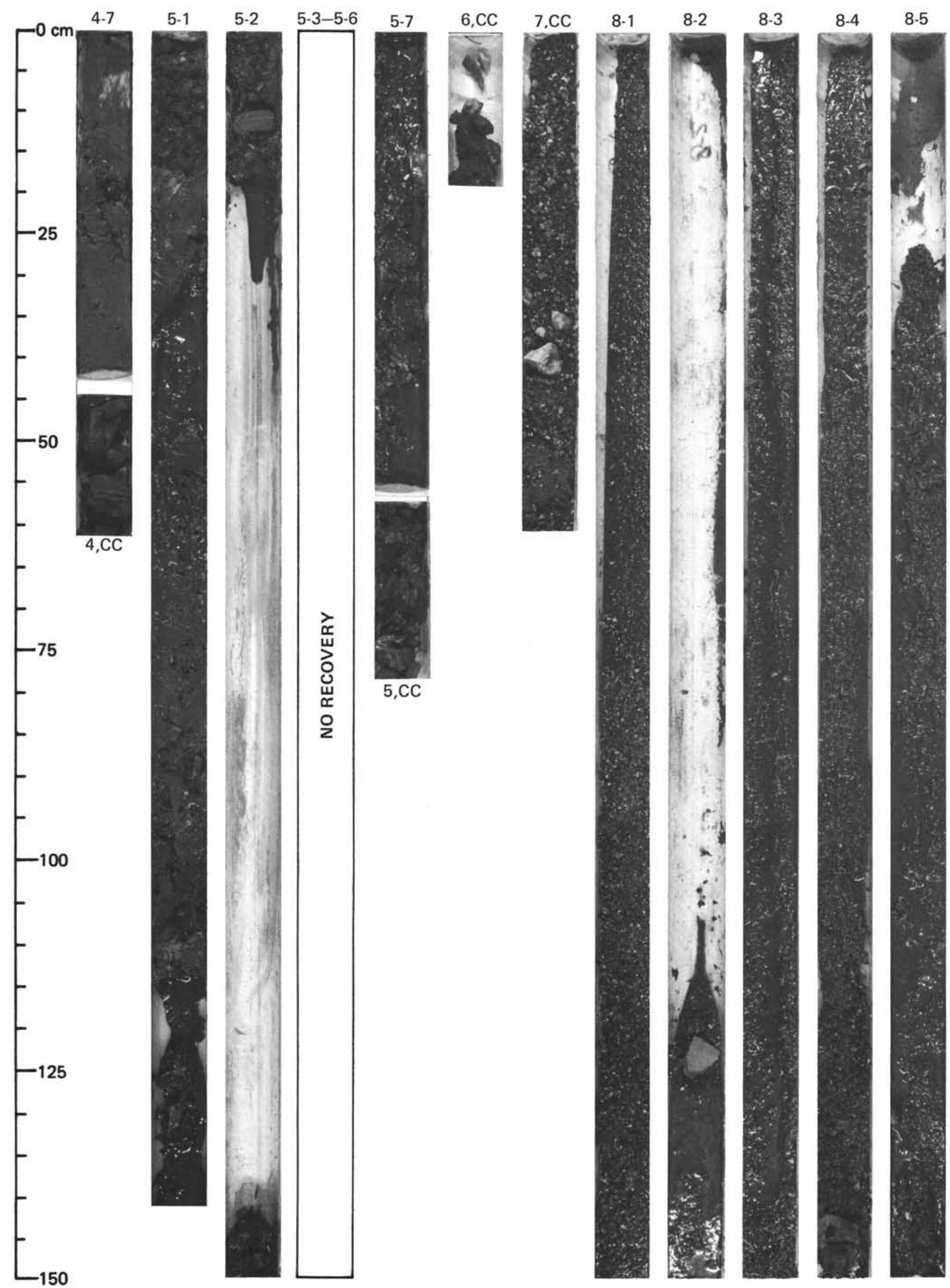


SITE 595 (HOLE 595A)

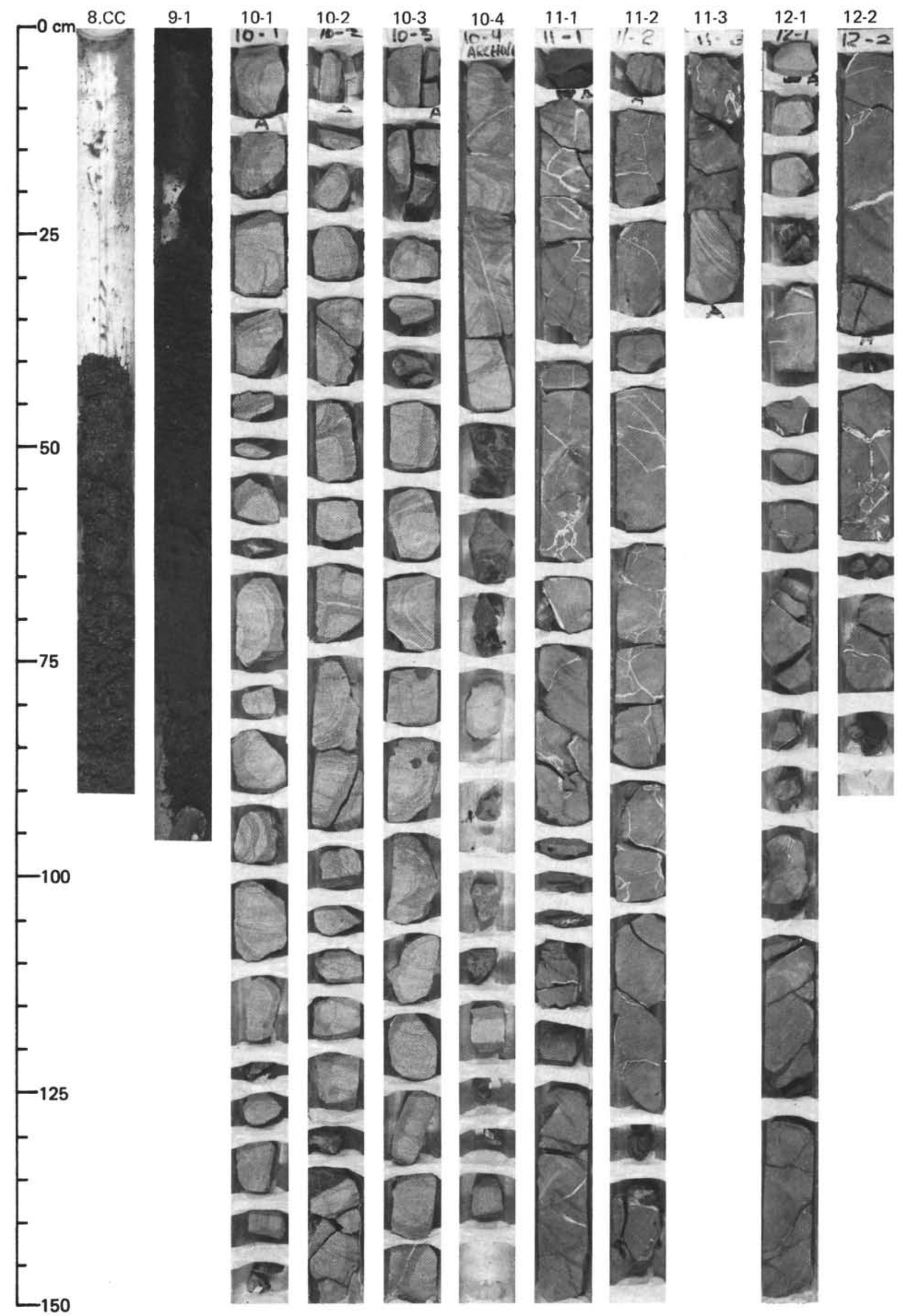


SITE 595 (HOLE 595B)

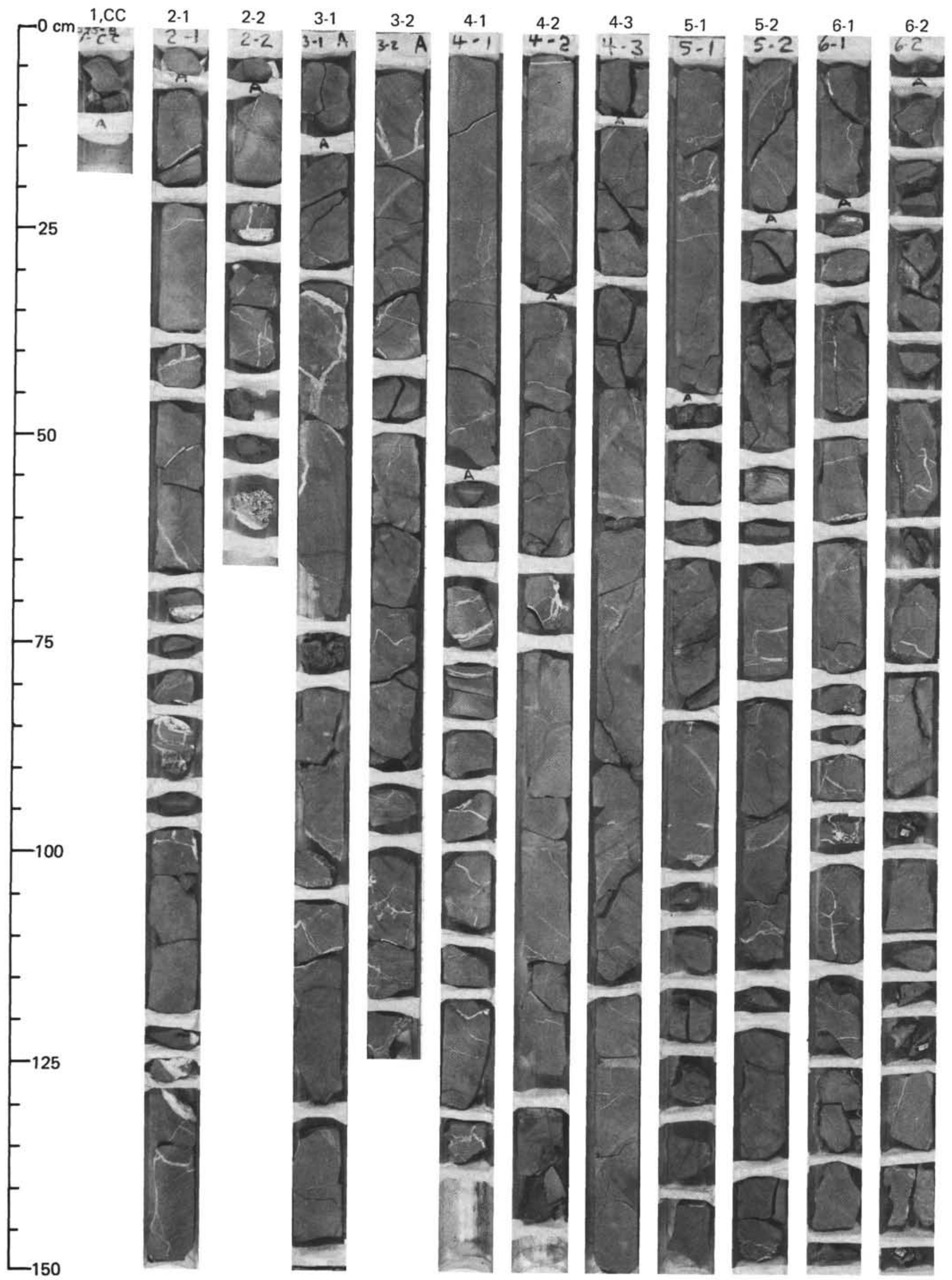


SITE 595 (HOLE 595B)

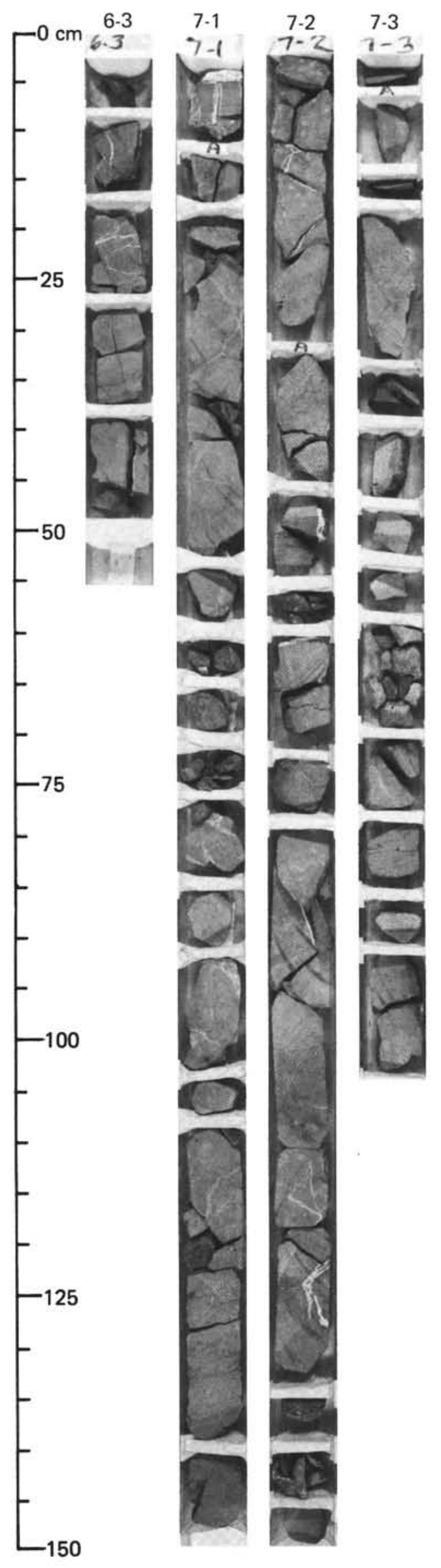

